\title{
Performance of structural stainless steel following a fire
}

\author{
Tom Molkens ${ }^{1}$, Katherine A. Cashell ${ }^{2}$, Mikko Malaska ${ }^{3}$, Mika Alanen ${ }^{3}$, Barbara Rossi ${ }^{4,5}$ \\ ${ }^{1}$ KU Leuven, Department of Civil Engineering, tom.molkens@,kuleuven.be \\ ${ }^{2}$ Brunel University London, Department of Civil and Environmental Engineering, \\ katherine.cashell@brunel.ac.uk \\ ${ }^{3}$ Tampere University, Faculty of Built Environment, mikko.malaska@tuni.fi,mika.alanen@tuni.fi \\ ${ }^{4}$ University of Oxford, Department of Engineering Science, barbara.rossi@new.ox.ac.uk \\ ${ }^{5}$ KU Leuven, Department of Civil Engineering, barbara.rossi@kuleuven.be
}

\section{Abstract}

Stainless steel offers excellent mechanical properties as well as corrosion resistance and performs better in a fire compared to carbon steel in that it retains its strength and stiffness for a longer duration. The current paper is focussed on the post-fire condition, which has received limited attention to date from the research community. The motivation for the work is to show that stainless steel elements that have been exposed to fire can be re-instated with minimal additional costs in a short time frame. The paper proceeds with a description of recent material tests into the residual properties of grade 1.4301 austenitic stainless steel, following exposure to elevated temperature. Two different types of test were conducted and these are described. Firstly, a series of tensile tests were completed on coupons taken from a loaded stainless steel beam previously examined under fire conditions. Secondly, a set of virgin coupons (i.e. which have not been previously heated or tested) were exposed to different levels of elevated temperature and cooling procedures. This is with a view to understanding the ability of structural elements made from this material to survive a fire and continue in service. The results are employed along with other data obtained from the literature to conduct a detailed study into the design considerations. The collected data includes information on the proof and ultimate strengths, ultimate strain and Young's modulus and the extent to which these are affected following the occurrence of a fire. The study is done for ferritic, austenitic and duplex stainless steel. By focusing on the effect of a fire on the mechanical properties after cooling using a statistical approach, safety factors are proposed together with a reduced reliability index based on economic and social considerations. 


\section{Keywords:}

Stainless steel, cellular beams, post-fire, retention factor, existing buildings, statistical approach, safety factor, reliability 


\section{Introduction}

Stainless steel is an increasingly popular material for load-bearing structural applications owing its wide range of attractive properties such as ductility, strength, and durability. As such, the many advantages of stainless steel as a construction material relative to other more traditional metals such as carbon steel are being readily acknowledged by researchers and practitioners. Whilst it was traditionally employed for its excellent corrosion resistance and aesthetic qualities, in more recent years stainless steel has also been used in applications where its excellent strength, stiffness, ductility and performance in fire can be exploited. Although it is more expensive in initial costs relative to carbon steel, it compares very favourably in terms of life-cycle costs [1] and also performance criteria [2].

The design of stainless steel structures is covered by a number of international design codes such as Eurocode 3 Part 1-4 [3] and also the comprehensive SCI stainless steel design manual [4]. Stainless steel structural sections are now readily available in a large number of grades with different properties, to satisfy various applications. Stainless steels are generally classified into five different groups according to their chemical composition and metallurgical structure. The most commonly used in structural applications are the austenitic, duplex and ferritic grades which are covered by the product standard for stainless steel [5]. The other two families, the martensitic and precipitation hardening grades, are rarely found in load-bearing structural designs. The most commonly used stainless steel in structural engineering is austenitic grade 1.4301 which offers high strength with considerable strainhardening and excellent ductility. It is also readily weldable and has excellent uniform corrosion resistance, without the need for any other additional protection.

The current paper deals with the behaviour and performance of austenitic structural stainless steel following exposure to fire and subsequent cooling. This is critically important information for the salvage and rehabilitation of real structures following a fire and is an increasingly important consideration as the demands for improved sustainability in construction continue to grow. A reliable database of information on the post-fire behaviour enables greater re-use of materials, structural elements and building components. In this context, new post-fire data is presented and combined with 
other experimental results to draw some conclusions and provide guidance. There are two fundamental research questions which are considered and answered in this work:

(i) How does stainless steel behave following exposure to fire conditions and how does it compare to carbon steel?

(ii) Are the post-fire mechanical properties influenced by the load history on the structural material?

The likelihood of a local fire occurring is approximately fourteen times greater than a fully developed whole-structure fire [6] and therefore the outcomes of this research can be employed to assess the behaviour and damage to critical components or parts of structures which may not be easy to replace.

This paper presents and discusses an extensive experimental programme which has been conducted to understand the behaviour of austenitic stainless steel following a fire, comprising two different test regimes. These were designed to capture the true post-fire behaviour for an in-service building or element, which may include some or all of the following steps: (i) static loading during normal service life, (ii) the application of elevated temperature during a fire, (iii) cooling of the member due, for example, to the intervention of the fire brigade, (iv) perhaps partial unloading of the member during reinstatement works, and finally (v) full re-loading in its new, post-fire, service life. Accordingly, in the first test series, a number of tensile tests were conducted on coupons extracted from a previously examined stainless steel structural member. This was a cellular beam made from grade 1.4301 stainless steel which was subjected to a standard fire test [7], and then allowed to cool naturally in the furnace. On the other hand, the second test series comprised tensile tests on 'virgin' coupons, which were made from the same batch of stainless steel plates that were used to make the cellular beam in the first test series. These were heated to a specified level of elevated temperature, then cooled down and mechanically tested in tension.

In the final part of the paper, the data from the post-fire tensile tests is examined with other available test results from the literature to assess and quantify the uncertainties in the material properties based on a probabilistic theory [8]. Based on this statistical analysis, through the partial factor method, 
characteristic values of retention factors applicable to the mechanical properties are proposed as well as post-fire safety factors. This paper follows the publication of a similar paper on the post-fire mechanical properties of carbon steel [9].

\section{Stainless steel structural members during a fire}

There has been significant research into the behaviour of stainless steel structural elements during a fire, although many of the studies are either numerical (when looking at large-scale behaviour) or smaller-scale material tests. Recently, for the first time in the public domain, a fire test was conducted on a full-scale stainless steel cellular beam made from grade 1.4301 austenitic stainless steel at the Fire Testing Laboratory at Tampere University in Finland. The beam was exposed to uniform static loading and a standard fire, as shown in Figure 1 [7]. The details and observations from this test are briefly outlined herein as they are relevant to later discussions as well as the post-fire material tests.

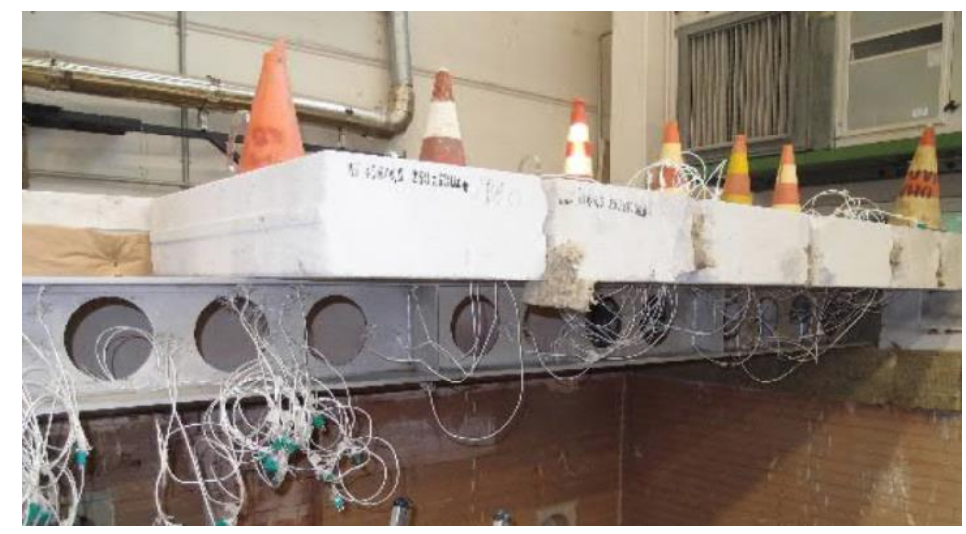

Figure 1 Cellular beam prior to fire testing [7].

The cellular beam was manufactured by welding grade 1.4301 austenitic stainless steel plates together. The beam was placed in the furnace and, in the first instance, was subjected to a static load with a load ratio of $30 \%$ of the design load. Then, the fire loading was applied, in accordance with the guidelines in EN 1363-1 (2012) and EN 1365-3 (1999) up until failure. The total length of the beam exposed to fire was $4000 \mathrm{~mm}$ and it had an overall depth of $290 \mathrm{~mm}$ and flange width of $300 \mathrm{~mm}$. The beam flange and web thicknesses were $14 \mathrm{~mm}$ and $8 \mathrm{~mm}$, respectively. The specimen also included $8 \mathrm{~mm}$ thick web stiffeners located at the beam supports and at the load application points on both sides of the web. The diameter of the circular openings was $200 \mathrm{~mm}$ and they were located at $300 \mathrm{~mm}$ centres. A series of 
$250 \mathrm{~mm}$ thick aerated concrete blocks were placed on top of the beam during testing, in order to simulate the floor slab and provide three-sided heating.

During the test, the temperatures were recorded by a range of thermocouples across the length and through the depth of the beam. The average maximum temperature measured in the cross-section during the test was $759^{\circ} \mathrm{C}$ and the maximum temperature in the web was recorded at $785^{\circ} \mathrm{C}$. The difference between the temperatures in the bottom and top flanges was about $250^{\circ} \mathrm{C}$, mainly owing to the presence of the concrete blocks on the top flange. Similar temperature development was recorded across all of the beam sections. The failure mechanism was initiated by web post buckling between the loading point and the beam support. Following a detailed numerical analysis, it was demonstrated that high failure temperatures are achieved for stainless steel cellular beams compared with similar carbon steel members owing to the higher strength retainment inherent to stainless steel [10].

For austenitic grade 1.4301, the nominal reduction factors for the proof strength $\left(f_{0,2}\right)$ and Young's modulus $(E)$, which are denoted as $k_{0.2, \theta, S S}$ and $k_{E, \theta, S S}$ respectively, are shown in Figure 2 [11], together with the equivalent values for carbon steel ( $k_{y, \theta, C S}$ and $k_{E, \theta, C S}$, respectively). It is clear that there is a steady reduction in strength and stiffness for stainless steel up to $800^{\circ} \mathrm{C}$ whereas, for carbon steel, there is less of a reduction in these properties compared with stainless steel up to $500^{\circ} \mathrm{C}$, and this is then followed by a very rapid drop.

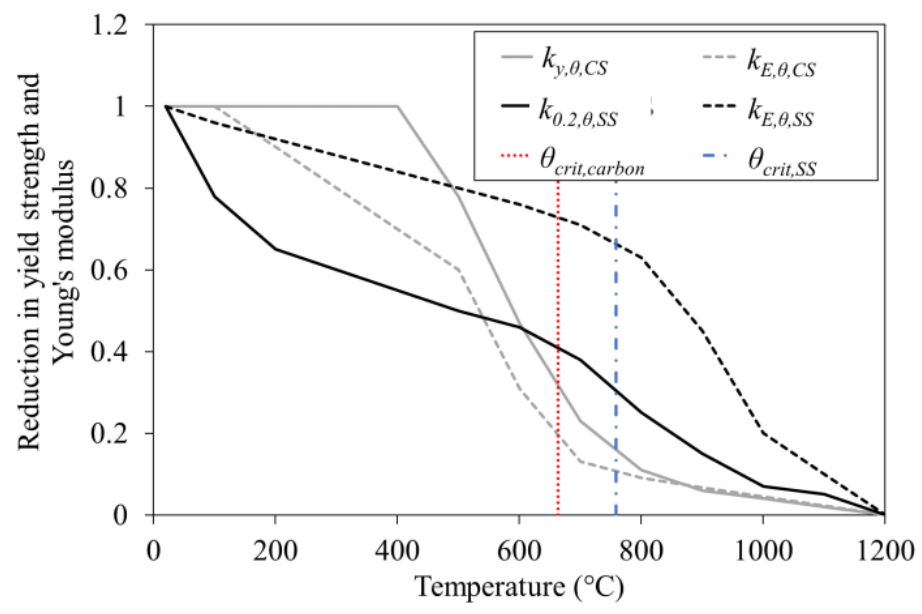

Figure 2 Reduction of yield strength and Young's modulus for carbon and grade 1.4301 austenitic stainless steel according to Eurocode 3 Part 1-2 (2004). 
As mentioned previously, a load ratio of $30 \%$ was applied to the tested cellular beam. The theoretical critical temperature using the guidance given in Eurocode 3 Part 1-2 (2004) for this beam is $777^{\circ} \mathrm{C}$ (compared with the average value of $759^{\circ} \mathrm{C}$ achieved during the experiment) whilst an identical beam made from carbon steel can theoretically survive until a temperature of $664^{\circ} \mathrm{C}$. Both theoretical critical temperatures are illustrated in Figure 2 by, respectively, a dashed and centre vertical grey line. In summary, the research conducted into this stainless steel cellular beam showed that the member performed better than a carbon steel equivalent beam, and survived for a longer period.

\section{Experimental programme}

As previously discussed, two test series were conducted in order to understand the post-fire behaviour of grade 1.4301 austenitic stainless steel under (i) loaded and (ii) virgin (i.e. not previously loaded) conditions. The coupons examined in both series originated from the same batch of stainless steel plates. These had a thickness of either $8 \mathrm{~mm}$ or $14 \mathrm{~mm}$, for use in the web and flange of the cellular beam, respectively. It is worth noting some of the key characteristics that are significant for stainless steel which exhibits non-linear stress-strain behaviour with large degrees of strain hardening. Stainless steel material properties are typically defined using 4 key parameters: Young's modulus $(E), 0.2 \%$ proof strength $\left(f_{0,2}\right)$, ultimate strength $\left(f_{u}\right)$ and total strain corresponding to the ultimate strength $\left(\varepsilon_{u}\right)$. This is in contrast to carbon steel which is usually described for design purposes using an elastic-perfectly plastic constitutive response, requiring only the yield strength, Young's modulus and the ultimate strain.

The ambient temperature material properties of both the $8 \mathrm{~mm}$ and $14 \mathrm{~mm}$ plates were determined by conducting tensile tests, in accordance with EN 10002-1 [12]. At least three repeats were carried out for each plate thickness and the average material properties, measured over a gauge length of $50 \mathrm{~mm}$, are presented in Table 1, in which $t$ is the plate thickness. The coefficient of variation values, defined as the ratio of the standard deviation to the mean, are also presented in the table in brackets after each term. This table includes the Young's modulus $(E), 0.2 \%$ proof strength $\left(f_{0,2}\right)$, ultimate strength $\left(f_{u}\right)$ and total strain corresponding to the ultimate strength $\left(\varepsilon_{u}\right)$ as well as the fracture strength $\left(f_{f r}\right)$ and corresponding strain $\left(\varepsilon_{f r}\right)$. A typical stress-strain curve from the tensile tests on the stainless steel is 
depicted in Figure 3(a) whilst a closer-view of the low strain range of these samples is also provided in Figure 3(b) to facilitate analysis later in this paper.

Table 1 Ambient material properties of the austenitic stainless steel plates (coefficient of variation values in brackets).

\begin{tabular}{|c|c|c|c|c|c|c|c|}
\hline & $\begin{array}{c}t \\
(\mathrm{~mm})\end{array}$ & $\begin{array}{c}E \\
\left(\mathrm{kN} / \mathrm{mm}^{2}\right)\end{array}$ & $\begin{array}{c}f_{0.2} \\
\left(\mathrm{~N} / \mathrm{mm}^{2}\right)\end{array}$ & $\begin{array}{c}f_{u} \\
\left(\mathrm{~N} / \mathrm{mm}^{2}\right)\end{array}$ & $\begin{array}{c}\varepsilon_{u} \\
(\%)\end{array}$ & $\begin{array}{c}f_{f r} \\
\left(\mathrm{~N} / \mathrm{mm}^{2}\right)\end{array}$ & $\begin{array}{c}\varepsilon_{f r} \\
(\%)\end{array}$ \\
\hline Web & 8 & $\begin{array}{l}186.8 \\
(0.03)\end{array}$ & $\begin{array}{l}269.1 \\
(0.02)\end{array}$ & $\begin{array}{l}625.7 \\
(0.02)\end{array}$ & $\begin{array}{c}59.0 \\
(0.06)\end{array}$ & $\begin{array}{l}366.6 \\
(0.02)\end{array}$ & $\begin{array}{c}67.2 \\
(0.06)\end{array}$ \\
\hline Flange & 14 & $\begin{array}{c}188.9 \\
(0.03)\end{array}$ & $\begin{array}{l}264.3 \\
(0.02)\end{array}$ & $\begin{array}{l}679.9 \\
(0.02)\end{array}$ & $\begin{array}{c}63.7 \\
(0.05)\end{array}$ & $\begin{array}{l}523.9 \\
(0.01)\end{array}$ & $\begin{array}{c}72.4 \\
(0.04)\end{array}$ \\
\hline
\end{tabular}

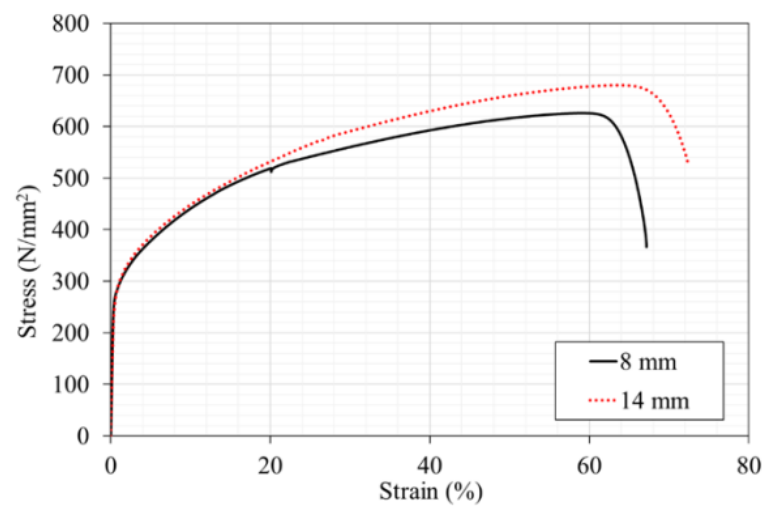

a)

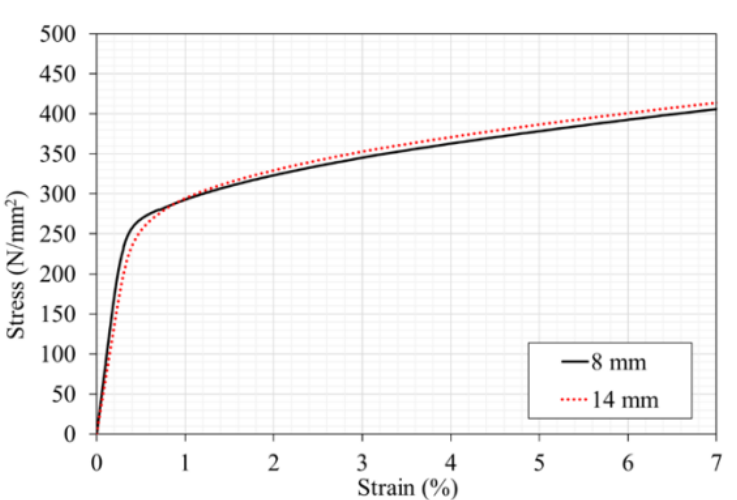

b)

Figure 3 Engineering stress-strain response for the stainless steel used for the web (8 $\mathrm{mm}$ ) and flange (14 mm) including a) the full range response and b) a closer view at the low strain range.

\subsection{Loaded specimens}

Earlier in this paper, an elevated temperature test programme on a stainless steel cellular beam was described. The test was terminated when the web posts buckled between the position of load application and the beam support. Figure 4(a) shows the deflected shape of the beam after testing and Figure 4(b) presents the failure mode forming an S-shape in the web between openings. No lateral deflection or local buckling of the beam top flange in compression was observed during the test. Plastic deformation of the top and bottom flanges concentrated in the region between the load application and the first circular openings on the failed side of the beam. After testing, this beam was allowed to cool naturally, in the furnace (CIF), and then a series of coupons were cut from the tested beam to facilitate the current study. A total of 18 tensile test coupons were cut and tested representing the areas of maximum bending moment and shear force in the beam, as shown in Figure 5. Three coupons were taken from each location, so that repeat tests could be conducted. The beam was tested under four point bending 
conditions with two concentrated applied loads which produced constant bending moments in the portion of the specimen between the loads (i.e. locations A, C and E in Figure 5) and there was constant shear in the outer regions (i.e. locations B, D and F in Figure 5).

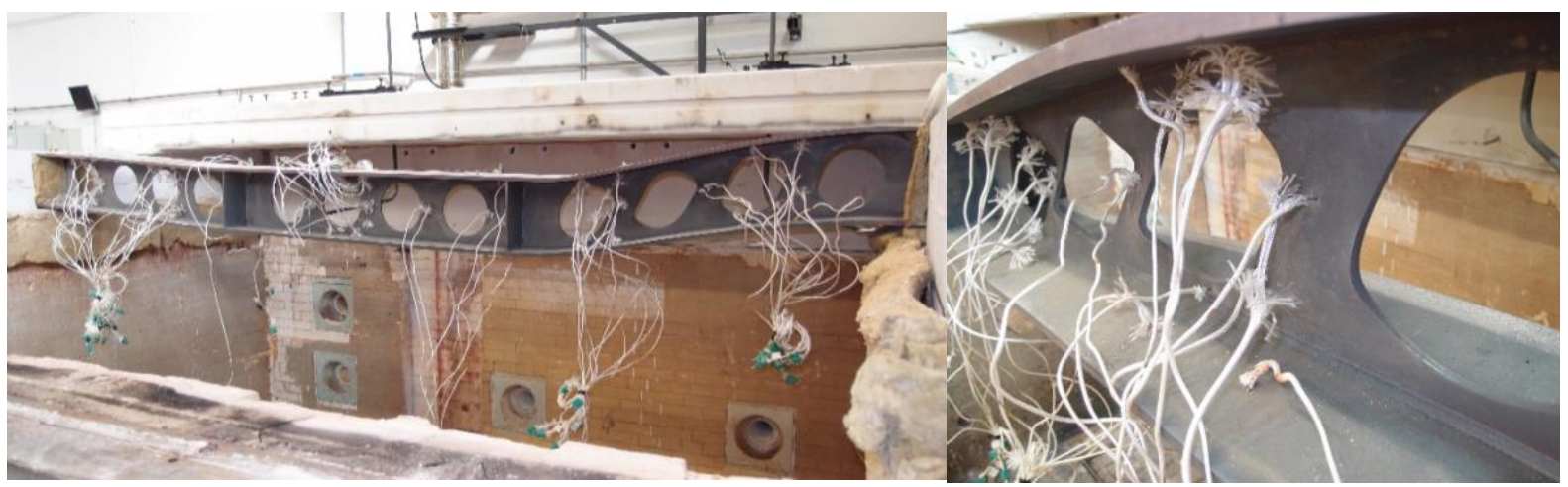

a)

b)

Figure 4: Cellular beam specimen after fire test: a) Steel beam after testing; b) Web post buckling failure mechanism
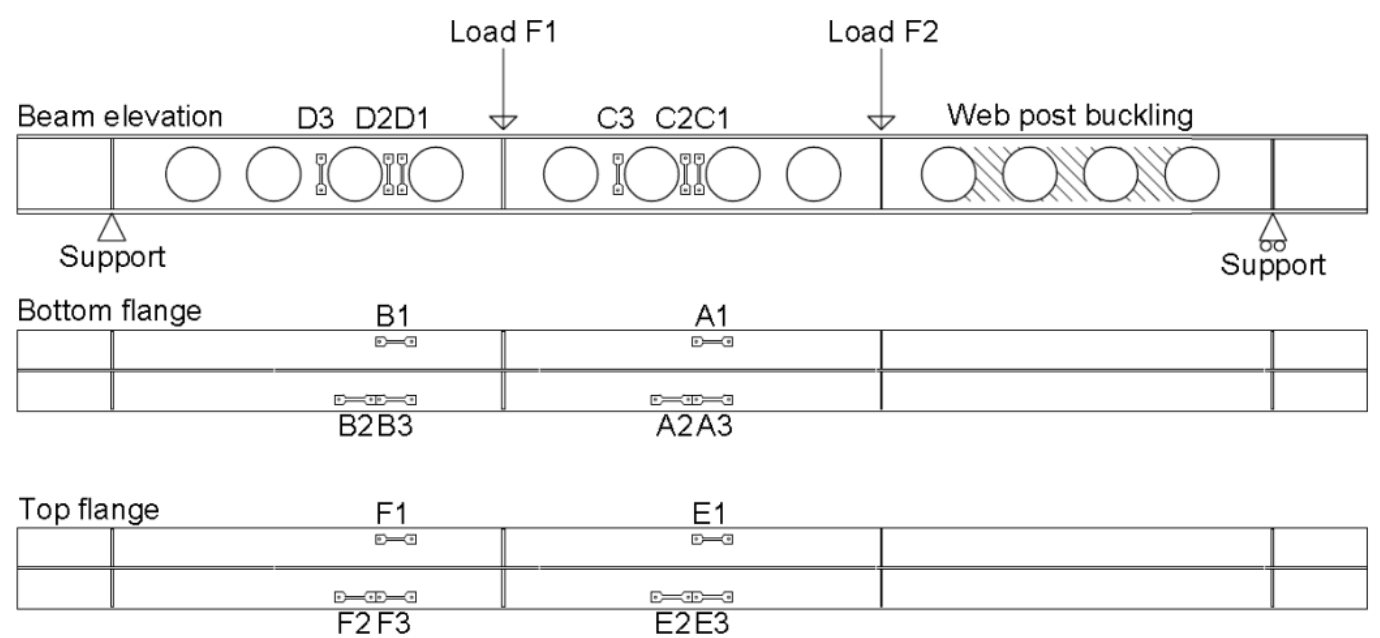

$\because$ Tensile test coupon

Figure 5: Cellular stainless steel beam and the locations of the tensile coupon.

Tensile coupon tests for the specimens were conducted at ambient temperature in accordance with EN 10002-1 (1990). An extensometer was used to measure the longitudinal tensile strains in the coupon specimens over a $25 \mathrm{~mm}$ gauge length, up to $7 \%$ total strain. Above this deformation level only the force and crosshead separation were monitored. The loading machine was operated in displacement control and the crosshead separation rate was $5 \mathrm{~mm} / \mathrm{min}$. The parallel length of the coupons was 
$120 \mathrm{~mm}$. Tensile loading was applied to the specimens until fracture and the percentage elongation after fracture was then determined after the tests.

The stress-strain curves from the tensile tests are presented in Figure 6 for (a) the bottom flange coupons, (b) the web coupons and (c) the top flange coupons. All the key properties measured during the tensile tests are also given in Table 2, such as Young's modulus, proof and ultimate strength values. The data includes the maximum temperature measured at the location of the coupons during the fire test $\left(\theta_{\exp }\right)$. The property values normalised against their corresponding mean values at ambient temperature (as in Table 1, denoted with a subscript 20, e.g, $E_{20}$ is the Young's modulus taken at ambient temperature) are also included in the table.

With reference to Figure 5, it is clear that the samples taken from similar locations (e.g. A1, A2 and A3 which are in the bottom flange, in the middle of the beam) show very similar results, as expected. One coupon, F2, displayed much higher proof strength value than F1 and F3. This was an unusual result and no evident explanation can be delivered to explain the deviation other than a human error. Table 1 shows a low coefficient of variation $(\mathrm{CoV})$ of only 0.02 for the test strength, on the basis of which the value of $\mathrm{F} 2$ can be considered as an outlier. Indeed, the deviation is about 5.6 times this $\mathrm{CoV}$ i.e. much higher than the typical limit factor 3. With reference to the data in Table 2, the flange coupons demonstrated that the previous load testing and exposure to high temperature $\left(\theta_{\exp }\right)$ did not have a significant effect on Young's modulus or proof strength values determined at different beam locations. For the top flange coupons, there was a slight increase of around 5\%. However, the value for the ultimate strength was reduced by approximately $10 \%$ in all locations. The maximum steel temperatures in these locations varied from $580{ }^{\circ} \mathrm{C}$ to $838^{\circ} \mathrm{C}$.

On the other hand, for the coupons taken from the web, there is a significant difference between the samples taken from the middle of the beam, which experienced high bending moments, and the region between the loading point and the support, which had high shear during the fire test. In both locations the values of Young's modulus and ultimate strength remained relatively unchanged from their ambient value, but the proof strength values were increased by approximately $5 \%$ and $40 \%$ in the middle of the beam and in the high shear zone, respectively. In the high shear zone, there is also a slight increase in 
the ultimate strength of around 5\%. The maximum steel temperatures in these locations varied from $779{ }^{\circ} \mathrm{C}$ to $834{ }^{\circ} \mathrm{C}$. As will be shown later in this paper, the proof strength of an unloaded coupon is decreased by approximately $10 \%$ following exposure to $750^{\circ} \mathrm{C}$ and subsequent cooling in the furnace. Therefore, it is clear that this significant increase in proof strength is due to loading, stresses and deformations in the beam web.

Figure 7 presents average post-fire stress-strain responses for each location of the tested beam including the bottom flange (BF), web and top flange (TF) in the middle of the beam and the shear zone (SZ). In the elastic range, all of the coupons regained the same levels of elastic stiffness, whilst the stainless steel in the web plate (which was $8 \mathrm{~mm}$ in thickness, compared with $14 \mathrm{~mm}$ in the flanges) had the most strength in the post-fire range. The degree of nonlinearity was also very similar, regardless of the location from which the coupon was extracted.

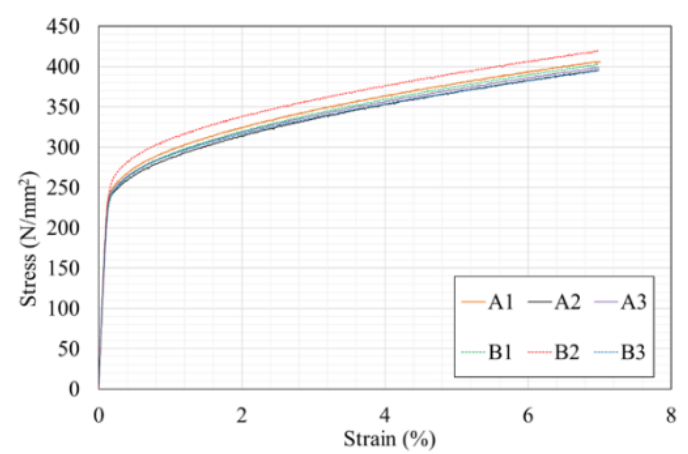

a)

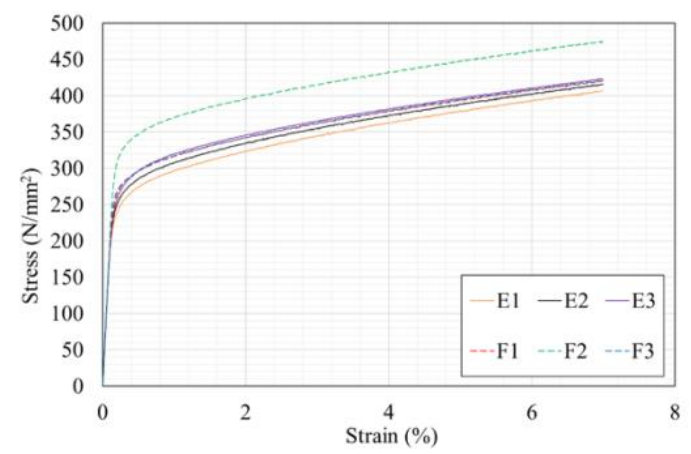

c)

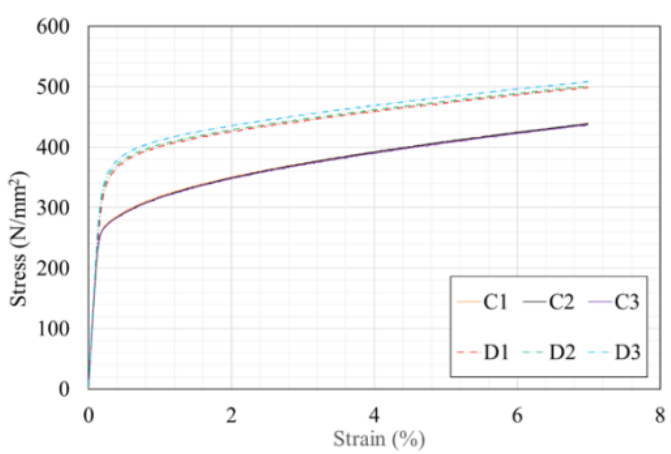

b)

Figure 6 Stress-strain response for the previously loaded and heated samples taken from a) the bottom flange b) the web and c) the top flange. 


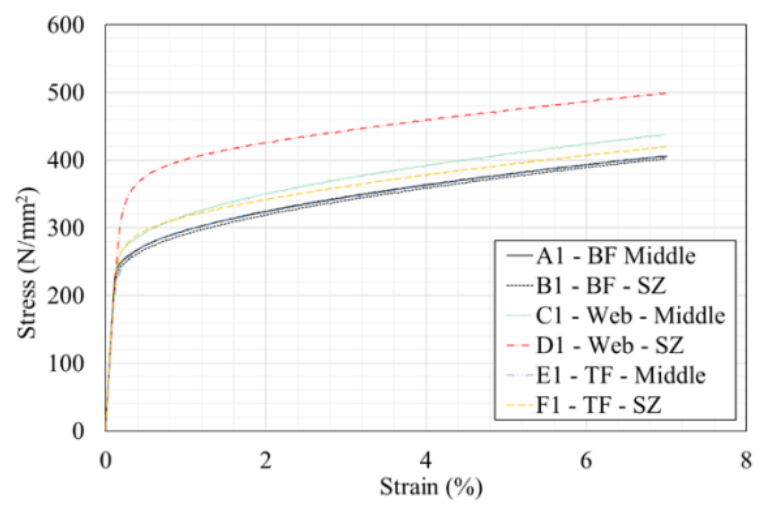

Figure 7 Influence of beam location on the post-fire stress strain response.

Table 2 Test results of coupons out of heated beam.

\begin{tabular}{lccccccc}
\hline Coupon & $\begin{array}{c}\theta_{\text {exp }} \\
\left({ }^{\circ} \mathrm{C}\right)\end{array}$ & $\begin{array}{c}E \\
\left(\mathrm{kN} / \mathrm{mm}^{2}\right)\end{array}$ & $E / E_{20}$ & $\begin{array}{c}f_{0.2} \\
\left(\mathrm{~N} / \mathrm{mm}^{2}\right)\end{array}$ & $f_{0.2} / f_{0.2,20}$ & $\begin{array}{c}f_{u} \\
\left(\mathrm{~N} / \mathrm{mm}^{2}\right)\end{array}$ & $f_{u} / f_{u, 20}$ \\
\hline A1 & 838 & 209.2 & 1.11 & 262 & 0.99 & 616 & 0.91 \\
\hline A2 & 832 & 183.4 & 0.97 & 256 & 0.97 & 613 & 0.90 \\
\hline A3 & 838 & 189.5 & 1.00 & 261 & 0.99 & 615 & 0.90 \\
\hline B1 & 784 & 191.7 & 1.01 & 259 & 0.98 & 613 & 0.90 \\
\hline B2 & 775 & 194.5 & 1.03 & 278 & 1.05 & 621 & 0.91 \\
\hline B3 & 784 & 185.6 & 0.98 & 258 & 0.98 & 605 & 0.89 \\
\hline E1 & 642 & 191.4 & 1.01 & 263 & 1.00 & 607 & 0.89 \\
\hline E2 & 636 & 197.3 & 1.04 & 275 & 1.04 & 611 & 0.90 \\
\hline E3 & 642 & 195.1 & 1.03 & 285 & 1.08 & 613 & 0.90 \\
\hline F1 & 580 & 194.2 & 1.03 & 287 & 1.09 & 613 & 0.90 \\
\hline F2 & 559 & 202.9 & 1.07 & 338 & 1.28 & 637 & 0.94 \\
\hline F3 & 580 & 196 & 1.04 & 287 & 1.09 & 612 & 0.90 \\
\hline C1 & 834 & 189.6 & 1.01 & 282 & 1.05 & 641 & 1.02 \\
\hline C2 & 834 & 182.1 & 0.97 & 282 & 1.05 & 638 & 1.02 \\
\hline C3 & 823 & 189 & 1.01 & 281 & 1.04 & 642 & 1.03 \\
\hline D1 & 794 & 182.4 & 0.98 & 368 & 1.37 & 657 & 1.05 \\
\hline D2 & 794 & 183.4 & 0.98 & 370 & 1.37 & 656 & 1.05 \\
\hline D3 & 779 & 206.7 & 1.11 & 376 & 1.40 & 662 & 1.06 \\
\hline
\end{tabular}

*Outlier

\subsection{Unloaded specimens}

In the previous section, the details of material tests taken from coupons that were extracted from a previously loaded and heated stainless steel cellular beam were described. In the current section, the second group of tensile coupon tests are described. The material for the coupons was not taken from the tested beam, but from the virgin plates that were used to manufacture of the cellular beam.

A total of 30 tests were conducted on both $8 \mathrm{~mm}$ and $14 \mathrm{~mm}$ thick samples (i.e. from the flange and web plates used in the beam), and the details are given in Table 3. Each coupon was initially heated to 
the target temperature $\left(\theta_{\exp }\right)$ in an oven at a rate of $10^{\circ} \mathrm{C} / \mathrm{min}$ and then allowed to soak at $\theta_{\exp }$ for 20 minutes, in accordance with the details given elsewhere [13]. After this, the coupons were generally quenched in cold water (CIW) to cool. To study the effect that cooling type has on the post-fire mechanical properties, additional tests were done at $750^{\circ} \mathrm{C}$ for both the $8 \mathrm{~mm}$ and $14 \mathrm{~mm}$ thicknesses, where the coupons were removed from the oven and allowed to cool naturally in air (CIA). Once the coupons were at room temperature, a standard tensile test was completed, in accordance with the procedure described in the literature [14], [13].

The results from the post-fire virgin (unloaded) coupon tests are given in Table 3, including the Young's modulus $(E), 0.2 \%$ proof strength $\left(f_{0,2}\right)$, ultimate strength $\left(f_{u}\right)$, corresponding ultimate strain $\left(\varepsilon_{u}\right)$, fracture strength $\left(f_{f r}\right)$ and corresponding fracture strain $\left(\varepsilon_{f r}\right)$. Three repeats were completed for each test, and the mean values are presented in the table and figure. The coefficient of variation is also given in brackets after each value in the table, and this is defined as the standard deviation divided by the corresponding mean value. Also included in the table are the property values normalised against their corresponding mean value at ambient temperature (as in Table 1), which are denoted with a subscript 20, e.g, $E_{20}$ is the Young's modulus taken at ambient temperature. An extensometer was used to measure the longitudinal tensile strains in the coupon specimens over a $50 \mathrm{~mm}$ gauge length, up to $10 \%$ total strain. Above this deformation level only the force and crosshead separation were monitored. The stress-strain curves from the tests are presented in Figure 8 for (a) the $8 \mathrm{~mm}$ samples and (b) the $14 \mathrm{~mm}$ coupons. 
Table 3 Test results of the coupons from virgin plates.

\begin{tabular}{|c|c|c|c|c|c|c|c|c|c|c|c|c|c|c|}
\hline$t(\mathrm{~mm})$ & $\theta_{\exp }\left({ }^{\circ} \mathrm{C}\right)$ & $\begin{array}{l}\text { Cooling } \\
\text { method }\end{array}$ & $\begin{array}{c}E \\
\left(\mathrm{kN} / \mathrm{mm}^{2}\right) \\
\end{array}$ & $E / E_{20}$ & $\begin{array}{c}f_{0.2} \\
\left(\mathrm{~N} / \mathrm{mm}^{2}\right)\end{array}$ & $f_{0.2} / f_{0.2,20}$ & $\begin{array}{c}f_{u} \\
\left(\mathrm{~N} / \mathrm{mm}^{2}\right)\end{array}$ & $f_{u} / f_{u, 20}$ & $\varepsilon_{u}(\%)$ & $\varepsilon_{u} / \varepsilon_{u, 20}$ & $\begin{array}{c}f_{f r} \\
\left(\mathrm{~N} / \mathrm{mm}^{2}\right)\end{array}$ & $\begin{array}{c}f_{f r} \\
/ f_{f r, 20}\end{array}$ & $\varepsilon_{f r}(\%)$ & $\varepsilon_{f r} / \varepsilon_{f r, 20}$ \\
\hline 8 & 20 & - & $\begin{array}{l}186.8 \\
(0.03) \\
\end{array}$ & 1.00 & $\begin{array}{l}269.1 \\
(0.02) \\
\end{array}$ & 1.00 & $\begin{array}{l}625.7 \\
(0.02) \\
\end{array}$ & 1.00 & $\begin{array}{c}59.0 \\
(0.06) \\
\end{array}$ & 1.00 & $\begin{array}{l}366.6 \\
(0.02) \\
\end{array}$ & 1.00 & $\begin{array}{c}67.2 \\
(0.06) \\
\end{array}$ & 1.00 \\
\hline 8 & 250 & CIW & $\begin{array}{l}200.9 \\
(0.02) \\
\end{array}$ & 1.12 & $\begin{array}{l}272.1 \\
(0.03) \\
\end{array}$ & 1.01 & $\begin{array}{l}632.3 \\
(0.04) \\
\end{array}$ & 1.01 & $\begin{array}{c}59.1 \\
(0.05) \\
\end{array}$ & 1.00 & $\begin{array}{l}457.7 \\
(0.03) \\
\end{array}$ & 1.25 & $\begin{array}{c}66.1 \\
(0.04) \\
\end{array}$ & 0.98 \\
\hline 8 & 500 & CIW & $\begin{array}{l}210.4 \\
(0.04)\end{array}$ & 1.18 & $\begin{array}{l}269.3 \\
(0.04)\end{array}$ & 1.00 & $\begin{array}{l}632.1 \\
(0.05)\end{array}$ & 1.01 & $\begin{array}{c}59.6 \\
(0.07)\end{array}$ & 1.01 & $\begin{array}{l}441.7 \\
(0.05)\end{array}$ & 1.20 & $\begin{array}{c}67.1 \\
(0.06)\end{array}$ & 1.00 \\
\hline 8 & 750 & CIW & $\begin{array}{l}184.1 \\
(0.05) \\
\end{array}$ & 1.03 & $\begin{array}{l}255.3 \\
(0.07) \\
\end{array}$ & 0.95 & $\begin{array}{l}639.3 \\
(0.03) \\
\end{array}$ & 1.02 & $\begin{array}{c}55.9 \\
(0.08) \\
\end{array}$ & 0.95 & $\begin{array}{l}497.2 \\
(0.06) \\
\end{array}$ & 1.36 & $\begin{array}{c}62.6 \\
(0.07)\end{array}$ & 0.93 \\
\hline 8 & 750 & CIA & $\begin{array}{l}203.7 \\
(0.05) \\
\end{array}$ & 1.14 & $\begin{array}{l}237.7 \\
(0.05) \\
\end{array}$ & 0.88 & $\begin{array}{l}613.6 \\
(0.07) \\
\end{array}$ & 0.98 & $\begin{array}{c}57.5 \\
(0.07) \\
\end{array}$ & 0.97 & $\begin{array}{l}454.4 \\
(0.03) \\
\end{array}$ & 1.24 & $\begin{array}{c}64.3 \\
(0.08) \\
\end{array}$ & 0.96 \\
\hline 14 & 20 & - & $\begin{array}{l}188.9 \\
(0.03) \\
\end{array}$ & 1.00 & $\begin{array}{l}264.3 \\
(0.02) \\
\end{array}$ & 1.00 & $\begin{array}{l}679.9 \\
(0.02) \\
\end{array}$ & 1.00 & $\begin{array}{c}63.7 \\
(0.05) \\
\end{array}$ & 1.00 & $\begin{array}{l}523.9 \\
(0.01) \\
\end{array}$ & 1.00 & $\begin{array}{c}72.4 \\
(0.04) \\
\end{array}$ & 1.00 \\
\hline 14 & 250 & CIW & $\begin{array}{l}198.9 \\
(0.04) \\
\end{array}$ & 1.05 & $\begin{array}{l}287.8 \\
(0.01) \\
\end{array}$ & 1.09 & $\begin{array}{l}684.7 \\
(0.06) \\
\end{array}$ & 1.01 & $\begin{array}{c}48.9 \\
(0.04)\end{array}$ & 0.77 & $\begin{array}{l}532.8 \\
(0.03) \\
\end{array}$ & 1.02 & $\begin{array}{c}57.1 \\
(0.06)\end{array}$ & 0.79 \\
\hline 14 & 500 & CIW & $\begin{array}{l}188.9 \\
(0.06) \\
\end{array}$ & 1.00 & $\begin{array}{l}281.8 \\
(0.04) \\
\end{array}$ & 1.07 & $\begin{array}{l}697.0 \\
(0.04) \\
\end{array}$ & 1.03 & $\begin{array}{c}63.9 \\
(0.03) \\
\end{array}$ & 1.00 & $\begin{array}{l}548.3 \\
(0.04) \\
\end{array}$ & 1.05 & $\begin{array}{c}72.8 \\
(0.06) \\
\end{array}$ & 1.00 \\
\hline 14 & 750 & CIW & $\begin{array}{l}186.6 \\
(0.05) \\
\end{array}$ & 0.99 & $\begin{array}{l}263.8 \\
(0.05) \\
\end{array}$ & 1.00 & $\begin{array}{l}705.8 \\
(0.08) \\
\end{array}$ & 1.04 & $\begin{array}{c}61.3 \\
(0.08) \\
\end{array}$ & 0.96 & $\begin{array}{l}582.1 \\
(0.08) \\
\end{array}$ & 1.11 & $\begin{array}{c}69.5 \\
(0.10) \\
\end{array}$ & 0.96 \\
\hline 14 & 750 & CIA & $\begin{array}{l}218.2 \\
(0.04) \\
\end{array}$ & 1.16 & $\begin{array}{l}257.8 \\
(0.06) \\
\end{array}$ & 0.98 & $\begin{array}{l}693.7 \\
(0.05) \\
\end{array}$ & 1.02 & $\begin{array}{c}63.2 \\
(0.05) \\
\end{array}$ & 0.99 & $\begin{array}{l}542.5 \\
(0.05) \\
\end{array}$ & 1.04 & $\begin{array}{c}71.7 \\
(0.08)\end{array}$ & 0.99 \\
\hline
\end{tabular}




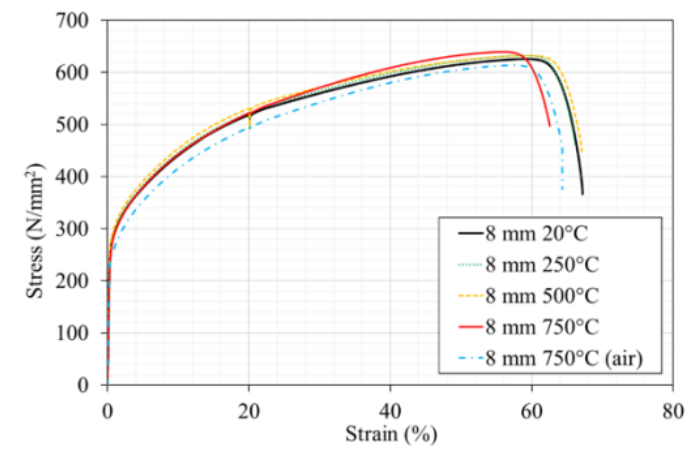

a)

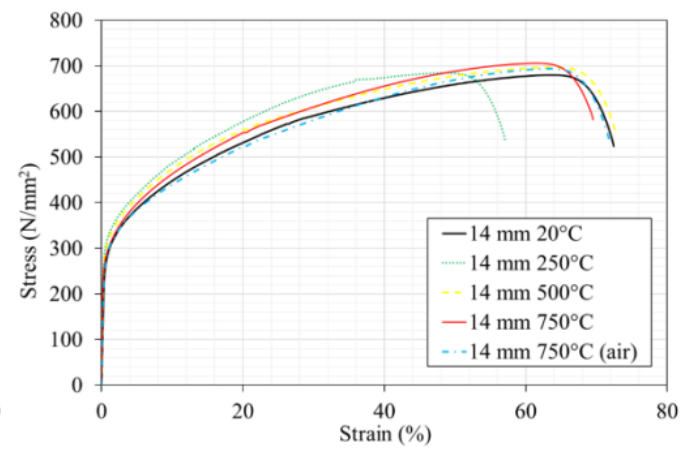

b)

Figure 8 Post-fire stress-strain curves on grade 1.4301 stainless steel for a) $8 \mathrm{~mm}$ coupons and b) $14 \mathrm{~mm}$ coupons.

With reference first to the stress-strain responses in Figure 8, it is clear that the general form of the constitutive relationships remains unchanged after exposure to elevated temperature and subsequent cooling, including the degree of nonlinearity and development of strain hardening which are characteristic to stainless steel. With reference to the data in Table 3, it is observed that the coefficient of variation ranges from 0.01 to 0.10 . The more specific observations from the data in Figure 7 and Table 3 are outlined hereafter.

- $\quad 0.2 \%$ proof stress: For the $8 \mathrm{~mm}$ coupons, the $0.2 \%$ proof stress generally remained the same until $500^{\circ} \mathrm{C}$. After this point, there was a $5 \%$ decrease in the value at $750^{\circ} \mathrm{C}$. On the other hand, for the $14 \mathrm{~mm}$ coupons, there was an increase in $f_{0.2}$ after exposure to $250^{\circ} \mathrm{C}$ and $500^{\circ} \mathrm{C}$ of $9 \%$ and $7 \%$, respectively. After exposure to higher temperatures, there was a very marginal decrease in $f_{0.2}$. For both the $8 \mathrm{~mm}$ and $14 \mathrm{~mm}$ coupons, there was a greater decrease in $f_{0.2}$ for the samples that were air cooled after being heated to $750^{\circ} \mathrm{C}$ compared to those that were quenched in water.

- $\quad$ Ultimate strength: The ultimate strength remained more or less the same across all temperature ranges examined for both the $8 \mathrm{~mm}$ and $14 \mathrm{~mm}$ coupons. The samples that were air cooled after being heated to $750^{\circ} \mathrm{C}$ demonstrated marginally lower ultimate strengths than those that were water-cooled this is similar to the observations that were made for $f_{0.2}$.

- Ultimate strain: It is clear from the data presented in Table 3 that the ultimate strain of the stainless steel material remains relatively unchanged from its ambient value even after exposure to $250^{\circ} \mathrm{C}$ or $500^{\circ} \mathrm{C}$. After it has been heated to $750^{\circ} \mathrm{C}$, there is a slight decrease in the ultimate strain of 
around $5 \%$ of the ambient value, for the samples that were cooled in water. This decrease is even less for those coupons that were cooled in air.

- Young's modulus: For both the $8 \mathrm{~mm}$ and $14 \mathrm{~mm}$ coupons, there was an increase in $E$ when the coupons were exposed to temperatures up to $500^{\circ} \mathrm{C}$. After exposure to $500^{\circ} \mathrm{C}, E$ increased by $18 \%$ for the $8 \mathrm{~mm}$ thick sample compared with the equivalent ambient value. However, after exposure to $750^{\circ} \mathrm{C}$, the $E$ value was actually $3 \%$ and $4 \%$ lower for the $8 \mathrm{~mm}$ and $14 \mathrm{~mm}$ coupons, respectively, compared with the corresponding values at ambient temperature. Generally, the effect on Young's modulus after a coupon has been exposed to elevated temperature was more noticeable for the $8 \mathrm{~mm}$ coupons than the $14 \mathrm{~mm}$ samples. With reference to the cooling method, for both 8 and $14 \mathrm{~mm}$ coupons, the increase in Young's modulus after exposure to $750^{\circ} \mathrm{C}$ was noticeably greater for the air-cooled coupons, most likely owing to the slower cooling method. This is converse to the $0.2 \%$ proof strength, which reduced in this same scenario. This is due to the metallurgical changes that occur with these changes in temperature conditions, as found also by other researchers [15].

- Fracture point: In terms of the eventual fracture of the coupon, the strength at which this occurred was generally greater for coupons that had been heated to higher degrees of elevated temperature. This increase was quite notable for both the $8 \mathrm{~mm}$ and $14 \mathrm{~mm}$ samples, reaching $23 \%$ and $11 \%$ respectively of the corresponding ambient values. This observation was less pronounced for the coupons that were air-cooled, similar to $f_{0.2}$ and $f_{u}$. Conversely, the coupons that were exposed to relatively higher temperatures experienced earlier fracture in terms of the $\varepsilon_{f r}$ value. In this instance, the fracture strain for the coupons that were air cooled was closer to the ambient value compared with the samples that were quenched in water.

In addition, it is possible to gain some insight into the influence of the load history on the post-fire mechanical properties of stainless steel, by comparing the data in the web given in Table 2 which reached around $780^{\circ} \mathrm{C}$ during the fire test (i.e. D1, D2 and D3) with the mechanical data for the $8 \mathrm{~mm}$ thick coupons in Table 3 which were exposed to $750^{\circ} \mathrm{C}$ and cooled in air (this is not exactly an identical scenario, but it is reasonably close to enable a comparison). Ideally, in order to get a comprehensive overview of the effect of the load-history, a detailed set of targeted tests studying the metallurgy as well 
as the heating distribution should be sought. Nevertheless, some initial observations can be made from the data presented in this paper. These are summarised as follows:

- $\quad 0.2 \%$ proof strength: for the unloaded samples, the ratio $f_{0.2} / f_{0.2,20}$ is 0.88 whereas, for the loaded samples, the corresponding data for D1, D2 and D3 were 1.37, 1.37 and 1.4 respectively. This clearly demonstrates a significant influence of the load history, the samples that were subjected to loading during the fire gained strength following exposure to high temperature, is most likely owing to metallurgical changes.

- Ultimate strength: A similar trend was observed for the ultimate strength although less pronounced than that for the $0.2 \%$ proof strength. For the unloaded samples, the ratio $f_{u} / f_{u, 20}$ is 0.98 whereas, for the loaded samples, the corresponding data for D1, D2 and D3 were 1.05, 1.05 and 1.06 respectively.

- Young's modulus: In contrast to the strength properties, for the unloaded samples, the Young's modulus increased by $14 \%$ following exposure to $750^{\circ} \mathrm{C}$ and subsequent cooling in air. For the loaded specimens, two of the three samples showed a lower Young's modulus after exposure to fire. The ratio $E / E_{20}$ is $0.98,0.98$, and 1.11 for D1, D2 and D3, respectively. Again, this is most likely due to changes in metallurgy and dislocation movements occurring during the exposure to high temperature and subsequent cooling, which varies depending on the load history. It is noteworthy that the conclusions drawn herein on the influence of load history on the post-fire properties of stainless steel, which have been discussed in the context of the web data, are also evidenced by the flange data given in Tables 2 and 3 .

In conclusion to this section, it is generally observed that the thickness of the sample, the method of cooling and the load history is quite impactful to the residual properties of the materials after exposure to temperature. For the samples considered in this study, it is shown that quenching the coupons in water rather than allowing the samples to cool naturally in air resulted in greater retention of the strength terms $\left(f_{0.2}, f_{u}\right.$ and $\left.f_{f r}\right)$ but the corresponding strain values were somewhat reduced. This is however based on comparison with only one sample CIA. 


\section{Methodology for the statistical evaluation of test data}

4.1 Characteristic values

A significant amount of test data has become available in the last decade on the mechanical behaviour of stainless steel in the post-fire condition, which provides an ideal basis for the current statistical evaluation. In the corresponding article focussed on the post-fire behaviour of carbon steel [9], the procedures that are used in this article to determine the characteristic values of the mechanical properties in accordance with Eurocode 0 (2015) are described. Then, the methodology to derive the post-fire characteristic values taking into account the variability in the post-fire situation are explained. For information, a similar study into the post-fire behaviour of carbon steel has also been conducted and the results are available elsewhere steel [9].

4.3 Reduction of mechanical properties during fire and recovery following subsequent cooling

In this section, the data presented previously is complemented by information obtained from the available literature to conduct a detailed statistical analysis of the behaviour of three stainless steel grades after exposure to elevated temperature and subsequent cooling. Following a comprehensive literature survey, a large set of data from approximately 270 post-fire material tests are studied, as outlined in Table 4. These data include samples taken from reinforcement, sheet, plate, cold-formed welded hollow sections and bolts. To facilitate discussion, the data are subdivided into 17 sets depending on the material type and post-treatments during fabrication under consideration.

In Table 4, each reference is characterised by a set number, the reference and year of publication, the stainless steel grade, soak time during which the specimen is kept at elevated temperature and the cooling regime. A number of different cooling regimes are employed including specimens that are cooled in air (CIA), cooled in the furnace (CIF), cooled in blanket (CIB) and cooled in water (CIW).

The graphs presented in Figure 9 represent the retention factors for (a) the yield strength $R_{0.2, \theta}$, (b) ultimate strength $R_{u, \theta}$, (c) ultimate strain $R_{\varepsilon u, \theta}$ and (d) Young's modulus $R_{E, \theta}$ at a temperature $\theta\left({ }^{\circ} \mathrm{C}\right)$. In this figure, each data point represents the retention factors from a specific test result and the various colours represent different source references. The red dashed lines are employed for the reduction of the material properties when the temperature rises. 
Table 4 List of data on post-fire behaviour of austenitic stainless steel.

\begin{tabular}{|c|c|c|c|c|}
\hline Reference & $\begin{array}{l}\text { Set } \\
\text { number }\end{array}$ & $\begin{array}{l}\text { Corresponding stainless } \\
\text { steel grade }\end{array}$ & $\begin{array}{l}\text { Soak time } \\
\text { (h) }\end{array}$ & Cooling regime \\
\hline \multirow[t]{2}{*}{ Felicetti et al. [16] } & 1 & 1.4307 cold worked rebars & 1.0 & CIF \\
\hline & 2 & 1.4307 hot rolled rebars & 1.0 & CIF \\
\hline \multirow[t]{3}{*}{ Wang et al. [15] } & 3 & 1.4301 flat part SHS & 0.5 & CIF \\
\hline & 4 & $\begin{array}{l}\text { Cold worked corner region } \\
\text { SHS }\end{array}$ & 0.5 & CIF \\
\hline & 5 & $\begin{array}{l}\text { Cold worked corner region } \\
\text { CHS }\end{array}$ & 0.5 & CIF \\
\hline Huang et al. [17] & 6 & $\begin{array}{l}1.4003 \text { flat part RHS and } \\
\text { SHS, }\end{array}$ & 0.33 & $\begin{array}{l}\text { CIA, CIF, CAF, } \\
\text { CIW }\end{array}$ \\
\hline Gao et al. [18] & 7 & 1.4301 flat part RHS, & 0.5 & CIA, CIF \\
\hline \multirow[t]{3}{*}{ Tao et al. [19] } & 8 & $\begin{array}{l}\text { Sheet } 1.4404,1.4307 \text { and } \\
\text { flat part SHS } 1.4307\end{array}$ & 0.5 & CIA \\
\hline & 9 & Sheet 1.4362 and 1.4462 & 0.5 & CIA \\
\hline & 10 & $\begin{array}{l}\text { Sheet and flat part SHS } \\
1.4003\end{array}$ & 0.5 & CIA \\
\hline Huang et al. [20] & 11 & Flat part RHS 1.4162 & $\begin{array}{l}0.33,1.0 \text { and } \\
3.0\end{array}$ & CIF \\
\hline \multirow[t]{2}{*}{ Hu et al. [21] } & 12 & Bolts $1.4301,1.4401$ & 0.42 & CIA \\
\hline & 13 & Bolts $1.4301,1.4401$ & 0.42 & CIW \\
\hline \multirow[t]{4}{*}{ Current paper } & 14 & $\begin{array}{l}\text { Welded loaded flange } \\
1.4301\end{array}$ & EN 1361-1* & CIF \\
\hline & 15 & Welded loaded web 1.4301 & EN 1361-1* & CIF \\
\hline & 16 & $\begin{array}{l}\text { Non-welded unloaded } \\
\text { flange } 1.4301\end{array}$ & 0.33 & CIW, CIA \\
\hline & 17 & $\begin{array}{l}\text { Non-welded unloaded web } \\
1.4301\end{array}$ & 0.33 & CIW, CIA \\
\hline
\end{tabular}

*Refers to specimens that were heated and cooled after failure in accordance with EN 1363-1 [22] 


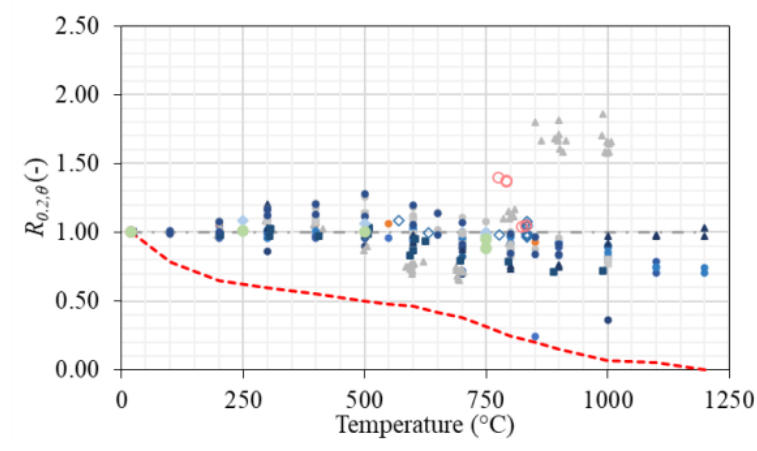

a)

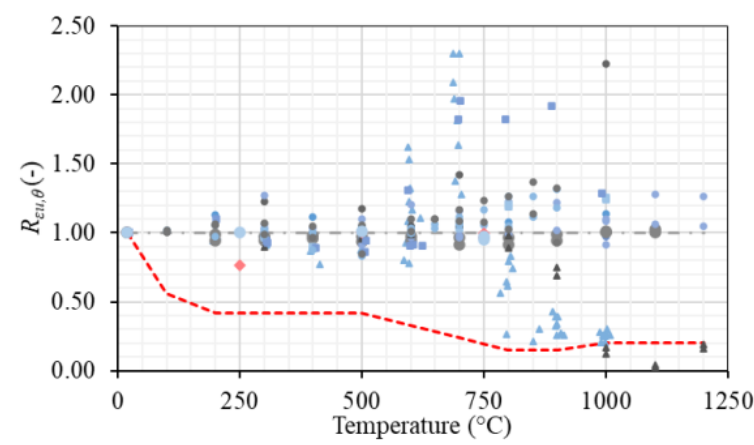

c)

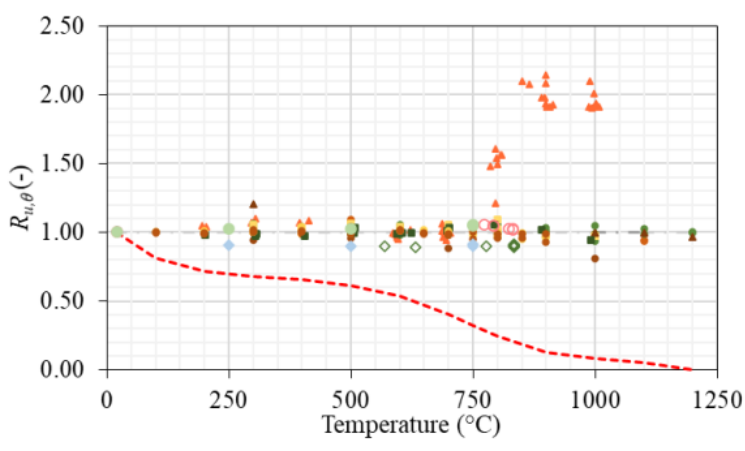

b)

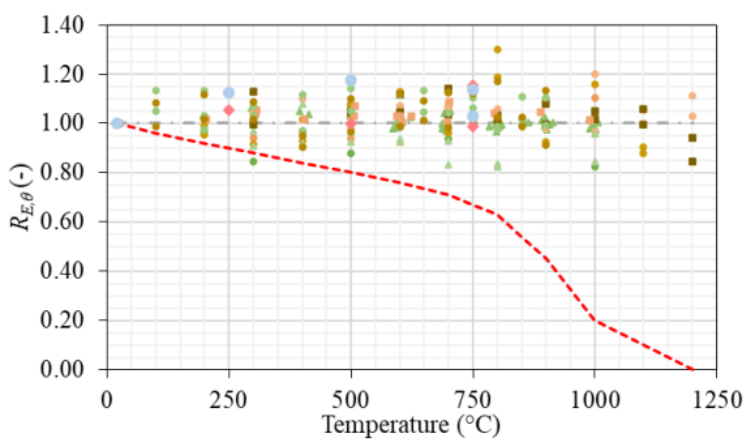

d)

Figure 9 Summary of retention factors for a) the yield strength $\left.R_{0.2, \theta}, b\right)$ ultimate strength $\left.R_{u, \theta}, c\right)$ ultimate strain $R_{\varepsilon u, \theta}$ and d) Young's modulus $R_{E, \theta}$ at a temperature using data from the literature [4].

The retention factor is defined as the value of the considered property after a full cycle including heating to a temperature $\theta\left({ }^{\circ} \mathrm{C}\right)$ and then cooling down, normalized by its value at ambient temperature before the cycle. It is determined as the product of the corresponding reduction factor (i.e. $k_{0.2, \theta, S S}, k_{u, \theta, S S}, k_{\varepsilon u, \theta, S S}$ and $k_{E, \theta, S S}$ for yield strength, ultimate strength, ultimate strain and Young's modulus, respectively) and a new factor named herein as the recovery factor $r_{\theta}$ (i.e. $r_{0.2, \theta}, r_{u, \theta}, r_{\varepsilon u, \theta}$ and $r_{E, \theta}$ for the yield strength, ultimate strength, ultimate strain and Young's modulus recovery factors, respectively). For the current analysis, the reduction factors are taken from the SCI stainless steel design guide [4] because these are more recent than the Eurocode 3 Part 1-4 [11] values and also include data on the ultimate strain which is not in the Eurocode. The reference temperature is the maximum temperature applied to the coupon, which is then held constant for at least 10 minutes. The data is rounded down to the $20^{\circ} \mathrm{C}$ increment, so a heating temperature of $505^{\circ} \mathrm{C}$, for example, is presented in the $500^{\circ} \mathrm{C}$ dataset. The recovery factor $r_{\theta}$ may reach values that are higher than unity when the properties are fully recovered after cooling down, as demonstrated in Figure 10. For ease of visualisation, the value of the recovery factor $r_{\theta}$ in this figure is limited to a maximum value of 4.0 . 


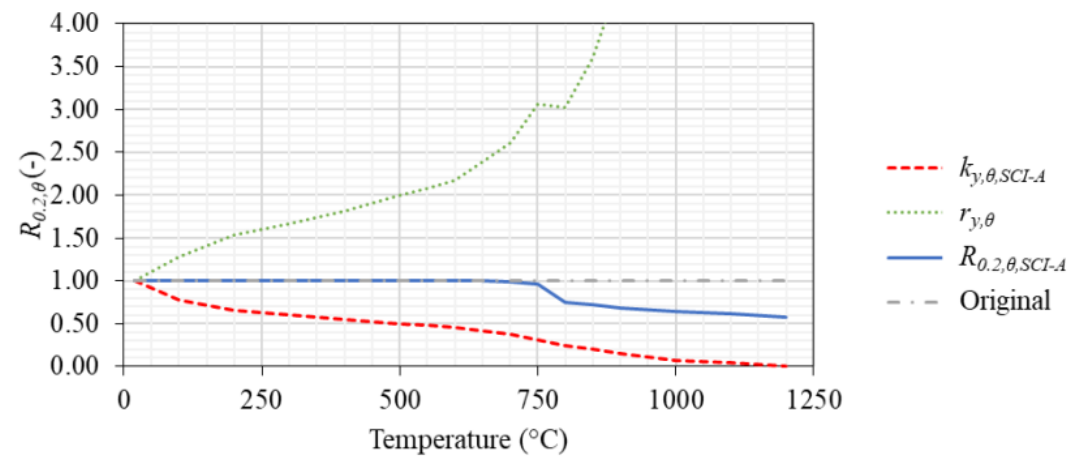

Figure 10 Reduction, recovery and retention factors for the $0.2 \%$ proof strength.

With reference to the data presented in Figure 8, a range of different material types are included as available in the literature, such as austenitic stainless steels (represented using solid circular shapes •), duplex stainless steels (solid squares $\mathbf{m}$ ) and ferritic stainless steels (which are presented as solid triangles $\boldsymbol{\Delta}$ ). Larger solid icons are employed for the test results described in section 0 of this paper (unloaded, CIW at 250,500 and $750^{\circ} \mathrm{C}$ ), while non-filled diamond $(\diamond)$ or circular symbols $(\circ)$ are used for the 'loaded test' data presented in section 0 (loaded, CIF), for the $14 \mathrm{~mm}$ and $8 \mathrm{~mm}$ coupons, respectively. A number of more detailed observations from the data given in these figures are outlined hereafter:

- $\quad 0.2 \%$ proof stress: it was shown earlier that stainless steels recover most of their properties after cooling down, provided that there is no initial heat treatment involved in their production processes or changes to their microstructure during heating and cooling. In Figure 9(a), it is shown that up to approximately $750^{\circ} \mathrm{C}$, all of the grades examined in this study almost completely recover their proof strength. After exposure to even higher temperatures (up to $1200^{\circ} \mathrm{C}$ ) and subsequent cooling, only about $30 \%$ of the original proof strength is lost (i.e. $R_{0.2, \theta} \approx 0.70$ ).

- Ultimate strength: The normalised tensile strength $\left(\mathrm{f}_{\mathrm{u}}\right)$ after cooling down, exhibits a more uniform distribution than the yield strength. The retention of this property is not affected by heating until $800^{\circ} \mathrm{C}$. With reference to the data in Figure $9(\mathrm{~b})$, it is evident that there is a group of ferritic stainless steels (solid triangles) which exhibit very high retention factors, even after exposure to very high temperatures. 
- $\quad$ Ultimate strain: Figure 9(c) shows that the normalised ultimate strain values after heating and then cooling remain relatively constant with a retention factor of unity, up until around $550^{\circ} \mathrm{C}$. Once the stainless steels are exposed to high temperatures, there is more scatter in the results, especially for the duplex and ferritic stainless steel test results. This will be discussed in more detail later.

- Young's modulus: it is shown in Figure 9(d) that Young's modulus recovers all of its stiffness over the whole temperature range studied herein.

It is noteworthy that for all of the data presented in Figure 9, there is increased scatter in the results following exposure to temperatures greater than $500^{\circ} \mathrm{C}$. Uncertainty in the results is not only reflected in the characteristic values but also is the safety factor which is discussed later in this paper.

\section{Retention factors}

In this section, each type of stainless steel is discussed in terms of its recovery of strength, stiffness and ductility following exposure to elevated temperature and subsequent cooling. Although the number of individual test results is significant at 260 , the number of data per heating temperature and per grade remains limited ( $<30$ for the different classifications). From a statistical perspective, a limited database may lead to unrepresentative deviations. Therefore, the proposed retention factor $R_{\theta}$ is adjusted by an operator in accordance with Eq. 1 where $\theta-1$ and $\theta+1$ are the preceding and following temperature intervals. This adjustment has the effect of (i) forcing a decrease in the retention factor and (ii) removing the influence of outlying values, by comparing it to the averaged value of its neighbouring intervals. The harmonizing or flattening effect of this operator is illustrated in Figure 11, depicting all collated results for $f_{0.2}$ with the raw calculated characteristic values (dotted line) and after the application of the aforementioned operator (solid line).

$$
R_{\theta, i}=\min \left(R_{\theta-1, k, i} ; \operatorname{MAX}\left(R_{\theta, k, i} ; \frac{R_{\theta-1, k, i}+R_{\theta+1, k, i}}{2}\right)\right)
$$




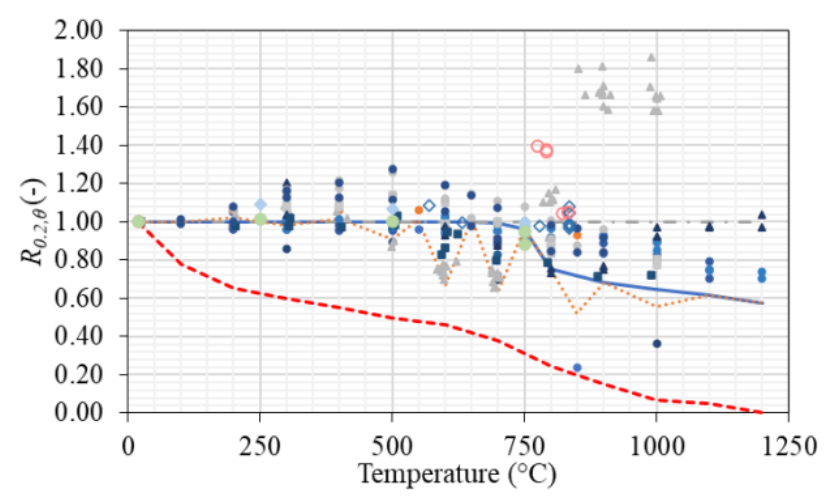

Figure 11 Effect of the adjustment operator on the proposed retention factors for the $0.2 \%$ proof strength values.

\subsection{Austenitic stainless steels}

The majority of the information available in the literature on the post-fire behaviour of stainless steel relates to the austenitic grades, including data from 151 individual tests (as presented in Table 4). These tests include specimens that were heated and then cooled either in air, in the furnace or in water. Different soaking periods have also been used across the various programmes. The test specimens which were subjected to a cold working process (which were some samples in set 1 and set 4) are excluded from this analysis. Figure 12 presents the post-fire properties for (a) the $0.2 \%$ proof strength (b) the ultimate strength (c) the ultimate strain and (d) Young's modulus for austenitic stainless steels. The corresponding reduction factor $\left(k_{0.2, \theta}\right)$ for grade 1.4301 austenitic stainless steel from the stainless steel design guide [4] is also included in the images, as a dashed line, as well as the proposed values for $R_{0.2, \theta}$ obtained by statistical analysis in the current work (solid line). Also, a summary of the proposed retention factors for austenitic stainless steels is given in Table 5.

For each of the properties considered in Figure 12, the following observations are made:

- $0.2 \%$ proof stress: In Figure $12(\mathrm{a})$, it is shown that the $0.2 \%$ proof strength $\left(\mathrm{f}_{0.2}\right)$ remains constant until the temperature exposure reaches $800^{\circ} \mathrm{C}$, and then reduced almost linearly to $70 \%$ of its initial value at $1200^{\circ} \mathrm{C}$.

- Ultimate strength: There is no evidence from the data in Figure 12(b) that the ultimate strength $\left(\mathrm{f}_{\mathrm{u}}\right)$ is influenced by exposure to elevated temperature and subsequent cooling. For the materials examined in this study, all retained their ultimate strength values following the heating and cooling cycles, even after exposure to very high temperatures. 
- Ultimate strain: It is evident in Figure 12(c) that the ultimate strain $\left(\varepsilon_{\mathrm{u}}\right)$ is constant until around $200^{\circ} \mathrm{C}$ and then decreases linearly from 1.0 to 0.93 between $200^{\circ} \mathrm{C}$ and $400^{\circ} \mathrm{C}$. After exposure to higher temperatures, this value remains constant until $1200^{\circ} \mathrm{C}$.

- Young's modulus: From Figure 12(d), it is observed that E starts to decrease even after exposure to relatively low elevated temperatures, but this reduction ceases at around $300^{\circ} \mathrm{C}$ after which the value remains constant at around $90 \%$ of the unheated value.
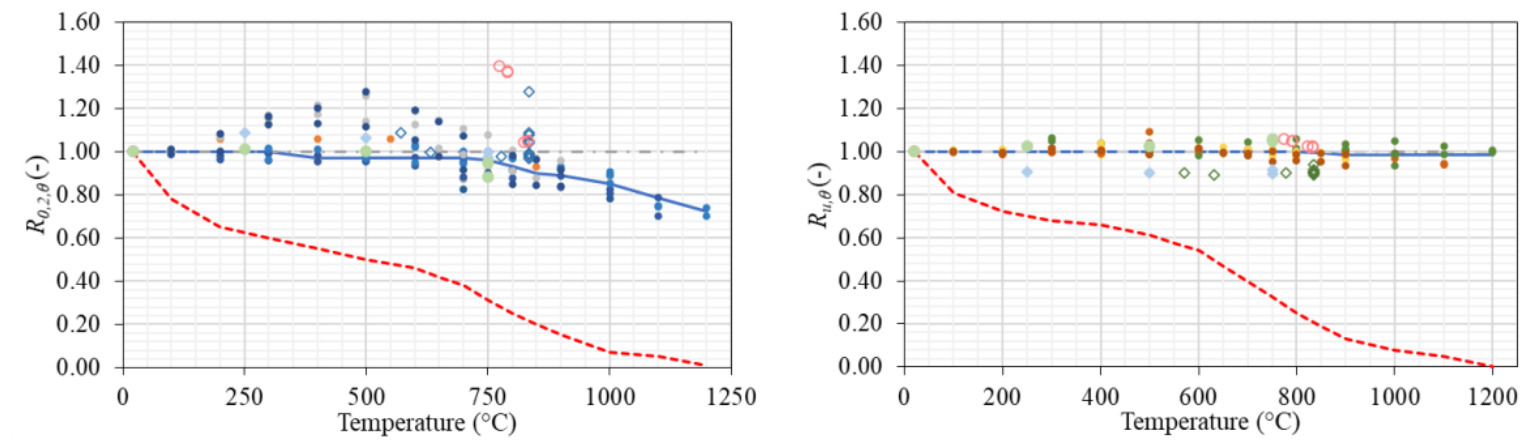

a)

b)
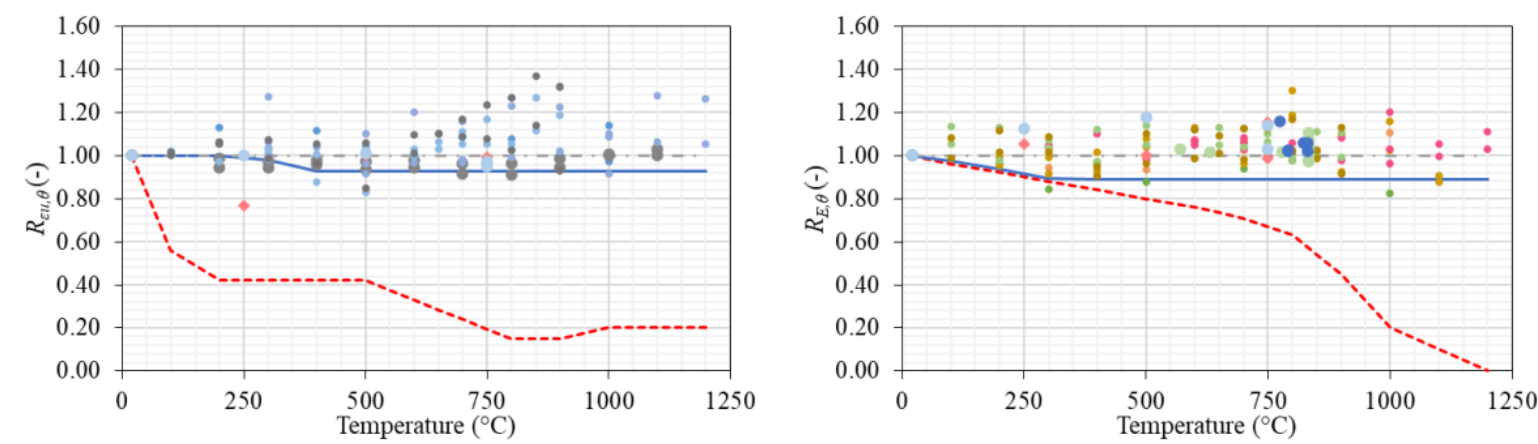

c)

d)

Figure 12 Material properties of austenitic stainless steel following exposure to elevated temperature and subsequent cooling, including a) $\left.\left.f_{0.2}, b\right) f_{u}, c\right) \varepsilon_{u}$ and d) $E$.

\subsection{Duplex stainless steels}

In comparison with the austenitic stainless steels, there is a notable dearth of data available on the duplex grades, with data from just 33 tests available in the literature. With reference to Table 4, these include coupons made from duplex stainless steel sheets made from grades 1.4362 and 1.4462 (both set 9) as well as grade 1.4162 (set 11) which came from rectangular hollow sections. Figure 13 presents the results for all of the post-fire tests on the duplex grade together with the reduction factor $k_{0.2, \theta}$ for grade 1.4362 from the stainless steel design guide [4] and the proposed values based on statistical analysis. 
As before, a summary of the proposed retention factors for duplex stainless steels is given in Table 5 . It is seen that these results show the same tendency as the austenitic stainless steels previously discussed and the principle observations are given as follows:

- $\quad 0.2 \%$ proof stress: This property begins to decrease after exposure to $500^{\circ} \mathrm{C}$ and above, reducing almost linearly to $80 \%$ of its initial value at $600^{\circ} \mathrm{C}$ and then remaining constant until $1000^{\circ} \mathrm{C}$.

- Ultimate strength: Almost no change is observed for the ultimate strength in these tests, similarly to the austenitic grades. At $1000^{\circ} \mathrm{C}$ a loss of only $4 \%$ is observed although it is noteworthy that this is based on only 3 tests.

- Ultimate strain: From Figure 13(c), it is clear that the ultimate strain decreases linearly from 1.0 to 0.8 between 20 and $700^{\circ} \mathrm{C}$. From $700^{\circ} \mathrm{C}$ and above, very high ultimate elongations are observed following the heating and cooling cycle.

- Young's modulus: From the data presented in Figure 13(d), Young's modulus reduces linearly to $90 \%$ of its original ambient value until the heating temperature reaches $300^{\circ} \mathrm{C}$ and then plateaus until $600^{\circ} \mathrm{C}$ after which it drops to $90 \%$ of the unheated value at $750^{\circ} \mathrm{C}$ and remains at this value thereafter.
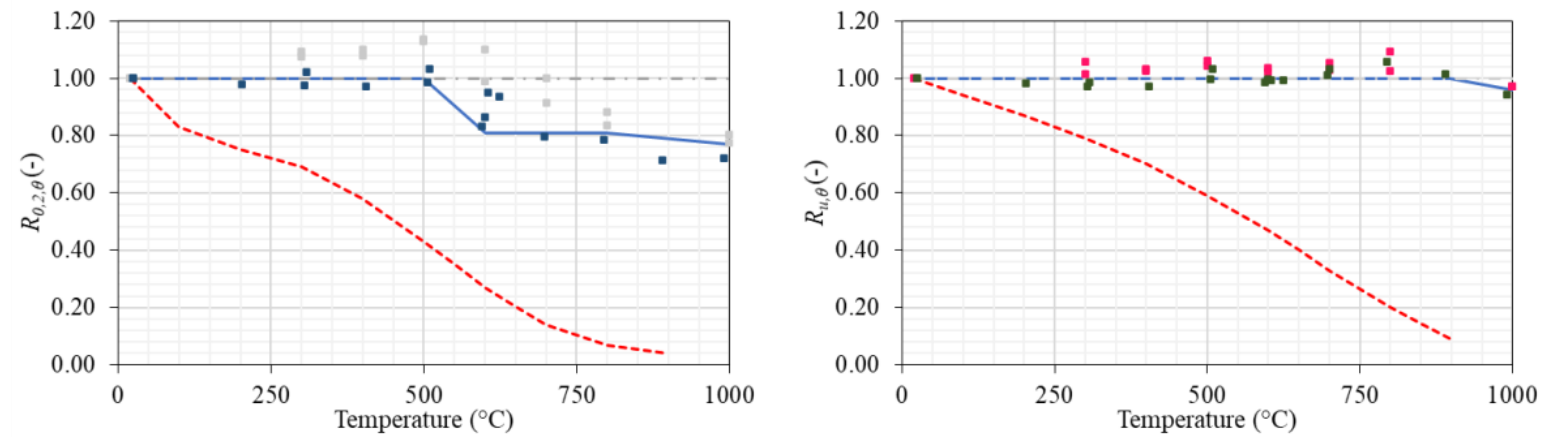

a)

b) 


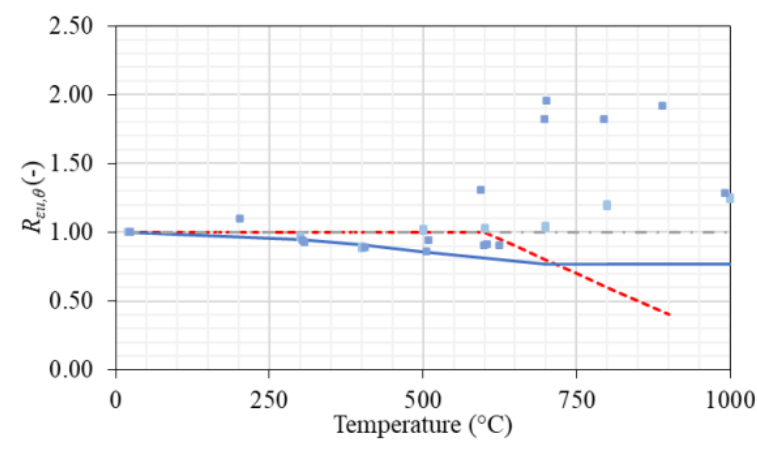

c)

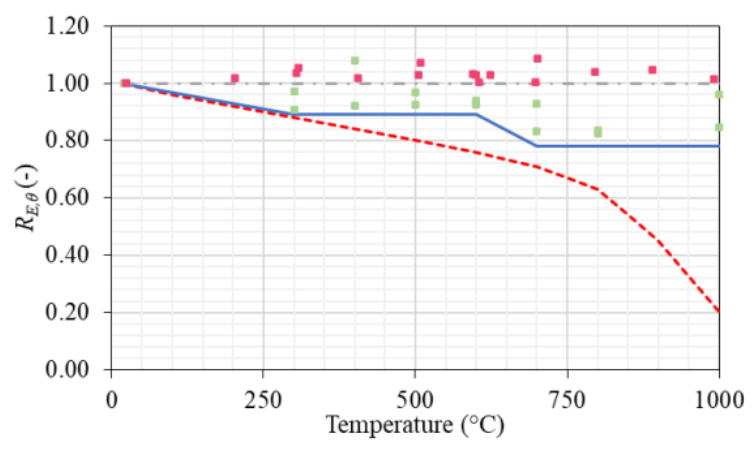

d)

Figure 13 Material properties of duplex stainless steel following exposure to elevated temperature and subsequent cooling, including a) $f_{0.2,}$ b) $f_{u}$, c) $\varepsilon_{u}$ and d) $E$.

\subsection{Ferritic stainless steels}

An extensive study into the post-fire behaviour of the ferritic stainless steel grade 1.4003 is available in sets 6 and 10 from the literature, as described in Table 4. In total the data from 75 tests are available and a number of different cooling procedures were investigated, including cooling in a furnace, air, forced air using a fan and in water [17]. In general, it was concluded that the mechanism of cooling has negligible effects on the post-fire mechanical properties, apart from for the ultimate strain. Figure 14 shows the results for all ferritic stainless steel post-fire coupon tests together with the reduction factor $k_{0.2, \theta}$ for grade 1.4003 [4] and the proposed values based on statistical analysis. Also, a summary of the proposed retention factors for ferritic stainless steels is given in Table 5 .

The behaviour of the ferritic stainless steel grades is notably different to the austenitic and duplex stainless steel grades due to a changing microstructure during the heating-cooling cycle. Between 850 and $1000^{\circ} \mathrm{C}$, the ferrite transforms to martensite [4]. Also, the grain size of the plated martensite increases with higher temperatures. It is the martensite which explains the increasing yield and ultimate strengths for the samples taken out of hollow sections (sets 6 and 10). The coupons out of the sheet (included in set 10) however do not show this behaviour. The main observations from Figure 14 are summarised as follows:

- $\quad 0.2 \%$ proof stress: From Figure $14(\mathrm{a})$, it is shown that $\mathrm{f}_{0.2}$ remains at its original value until exposure to around $500^{\circ} \mathrm{C}$ after which it reduced to a value of around $65 \%$ of the original value at $700^{\circ} \mathrm{C}$. From $800^{\circ} \mathrm{C}$, the samples began to regain their strengths although this is not taken into account 
in the proposed final value of the retention factor. The regain of strength is sometimes remarkable above $850^{\circ} \mathrm{C}$, owing to the increased presence of martensite in this range.

- $\quad$ Ultimate strength: For the ultimate strength $f_{u}$, no reduction in this property is observed following the heating and cooling cycle, which is similar to the behaviour of austenitic and duplex grades.

- Ultimate strain: With reference to Figure 14(c), it is shown that the ultimate strain remains constant at its original value until the heating temperature of around $500^{\circ}$. Then, after exposure of between $500^{\circ} \mathrm{C}$ and $750^{\circ} \mathrm{C}$, very high ultimate strains are reached after cooling. However, the proposed retention values do not allow for increase in ultimate strain from the original values, and therefore ignore this rise. There is then a steady decrease in the ultimate strain to a value of zero at $1100^{\circ} \mathrm{C}$.

- Young's modulus: In Figure 14(d) it is shown there is very little change in E until the heating temperature is $1100{ }^{\circ} \mathrm{C}$, and then it reduces to $80 \%$ of its initial value at $1200^{\circ} \mathrm{C}$.
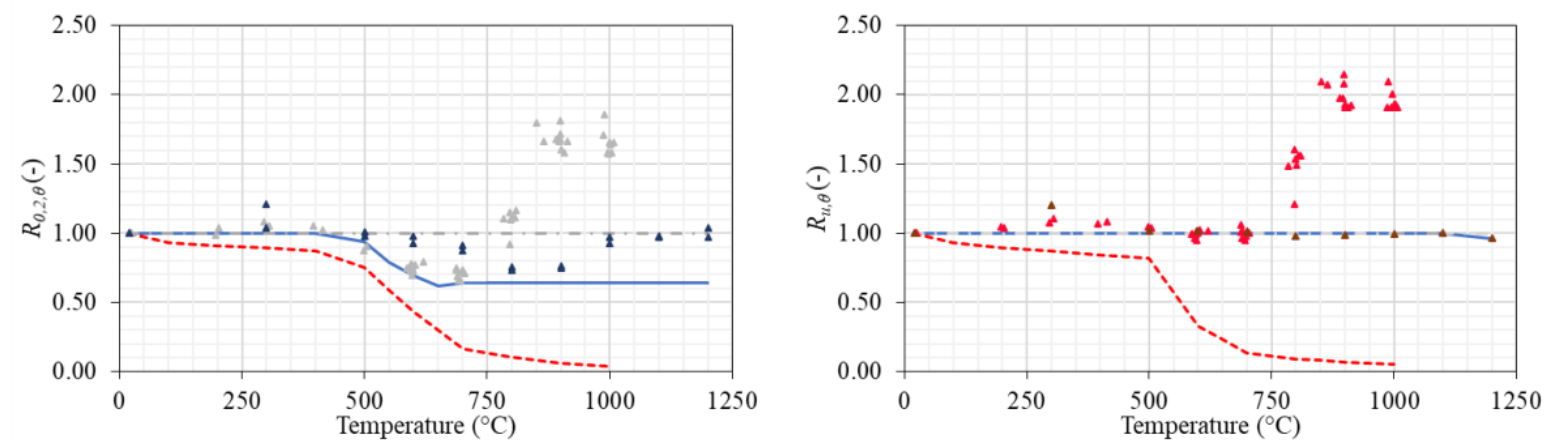

a)

b)
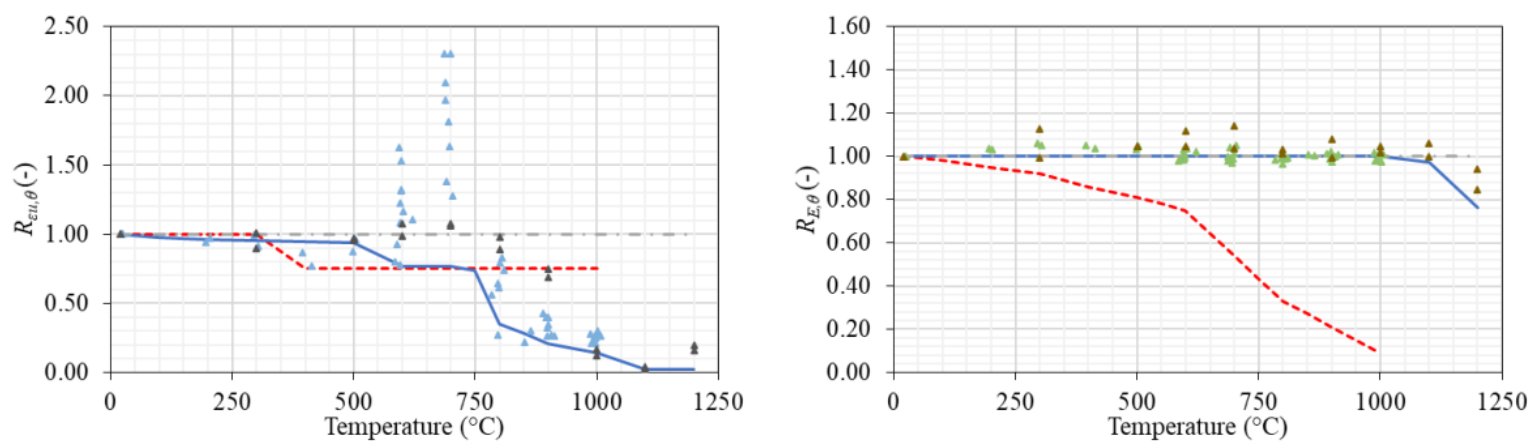

c)

d)

Figure 14 Material properties of ferritic stainless steel following exposure to elevated temperature and subsequent cooling, including a) $\left.\left.f_{0.2}, b\right) f_{u}, c\right) \varepsilon_{u}$ and d) $E$. 
Table 5 Retention factors for different families of stainless steels after exposure to elevated temperature $\theta$ (stainless steel temperature) and subsequent cooling.

\begin{tabular}{|c|c|c|c|c|}
\hline $\begin{array}{l}\text { Exposed steel } \\
\text { temperature } \theta\end{array}$ & $\begin{array}{c}\text { Retention factor } \\
\text { for proof strength } \\
\qquad R_{0,2, \theta} \\
\end{array}$ & $\begin{array}{c}\text { Retention factor for } \\
\text { the slope of the } \\
\text { linear elastic range } \\
R_{E, \theta} \\
\end{array}$ & $\begin{array}{c}\text { Retention factor } \\
\text { for tensile strength } \\
\qquad R_{u, \theta} \\
\end{array}$ & $\begin{array}{c}\text { Retention factor } \\
\text { for the elongation at } \\
\text { the tensile strength } \\
\qquad R_{\varepsilon u, \theta}\end{array}$ \\
\hline \multicolumn{5}{|c|}{ Austenitic stainless steels - Grades $1.4301,1.4307,1.4401,1.4404$} \\
\hline $20^{\circ} \mathrm{C}$ & 1.000 & 1.000 & 1.000 & 1.000 \\
\hline $100^{\circ} \mathrm{C}$ & 1.000 & 0.976 & 1.000 & 1.000 \\
\hline $200^{\circ} \mathrm{C}$ & 1.000 & 0.935 & 1.000 & 1.000 \\
\hline $300^{\circ} \mathrm{C}$ & 1.000 & 0.896 & 1.000 & 0.978 \\
\hline $400^{\circ} \mathrm{C}$ & 0.971 & 0.890 & 1.000 & 0.928 \\
\hline $500^{\circ} \mathrm{C}$ & 0.971 & 0.890 & 1.000 & 0.928 \\
\hline $600^{\circ} \mathrm{C}$ & 0.971 & 0.890 & 1.000 & 0.928 \\
\hline $700^{\circ} \mathrm{C}$ & 0.971 & 0.890 & 0.999 & 0.928 \\
\hline $800^{\circ} \mathrm{C}$ & 0.932 & 0.890 & 0.999 & 0.927 \\
\hline $900^{\circ} \mathrm{C}$ & 0.890 & 0.890 & 0.987 & 0.927 \\
\hline $1000^{\circ} \mathrm{C}$ & 0.850 & 0.890 & 0.984 & 0.927 \\
\hline $1100^{\circ} \mathrm{C}$ & 0.786 & 0.890 & 0.984 & 0.927 \\
\hline $1200^{\circ} \mathrm{C}$ & 0.721 & 0.890 & 0.984 & 0.927 \\
\hline \multicolumn{5}{|c|}{ Duplex stainless steels - Grades 1.4162.1.4362. 1.4462} \\
\hline $20^{\circ} \mathrm{C}$ & 1.000 & 1.000 & 1.000 & 1.000 \\
\hline $100^{\circ} \mathrm{C}$ & 1.000 & 0.963 & 1.000 & 0.983 \\
\hline $200^{\circ} \mathrm{C}$ & 1.000 & 0.927 & 1.000 & 0.967 \\
\hline $300^{\circ} \mathrm{C}$ & 1.000 & 0.890 & 1.000 & 0.950 \\
\hline $400^{\circ} \mathrm{C}$ & 1.000 & 0.890 & 1.000 & 0.908 \\
\hline $500^{\circ} \mathrm{C}$ & 1.000 & 0.890 & 1.000 & 0.862 \\
\hline $600^{\circ} \mathrm{C}$ & 0.810 & 0.890 & 1.000 & 0.810 \\
\hline $700^{\circ} \mathrm{C}$ & 0.810 & 0.780 & 1.000 & 0.770 \\
\hline $800^{\circ} \mathrm{C}$ & 0.810 & 0.780 & 1.000 & 0.770 \\
\hline $900^{\circ} \mathrm{C}$ & 0.790 & 0.780 & 1.000 & 0.770 \\
\hline $1000^{\circ} \mathrm{C}$ & 0.770 & 0.780 & 0.960 & 0.770 \\
\hline $1100^{\circ} \mathrm{C}$ & 0.000 & 0.000 & 0.000 & 0.000 \\
\hline $1200^{\circ} \mathrm{C}$ & 0.000 & 0.000 & 0.000 & 0.000 \\
\hline \multicolumn{5}{|c|}{ Ferritic stainless steels - Grade 1.4003} \\
\hline $20^{\circ} \mathrm{C}$ & $\overline{1.000}$ & 1.000 & 1.000 & 1.000 \\
\hline $100^{\circ} \mathrm{C}$ & 1.000 & 1.000 & 1.000 & 0.979 \\
\hline $200^{\circ} \mathrm{C}$ & 1.000 & 1.000 & 1.000 & 0.960 \\
\hline $300^{\circ} \mathrm{C}$ & 1.000 & 1.000 & 1.000 & 0.952 \\
\hline $400^{\circ} \mathrm{C}$ & 1.000 & 1.000 & 1.000 & 0.946 \\
\hline $500^{\circ} \mathrm{C}$ & 0.940 & 1.000 & 1.000 & 0.940 \\
\hline $600^{\circ} \mathrm{C}$ & 0.690 & 1.000 & 1.000 & 0.770 \\
\hline $700^{\circ} \mathrm{C}$ & 0.640 & 1.000 & 1.000 & 0.770 \\
\hline $800^{\circ} \mathrm{C}$ & 0.640 & 1.000 & 1.000 & 0.350 \\
\hline $900^{\circ} \mathrm{C}$ & 0.640 & 1.000 & 1.000 & 0.210 \\
\hline $1000^{\circ} \mathrm{C}$ & 0.640 & 1.000 & 1.000 & 0.140 \\
\hline $1100^{\circ} \mathrm{C}$ & 0.640 & 0.971 & 1.000 & 0.020 \\
\hline $1200^{\circ} \mathrm{C}$ & 0.640 & 0.760 & 0.964 & 0.020 \\
\hline
\end{tabular}




\subsection{Comparison with the post-fire behaviour of carbon steel}

As mentioned previously, a similar study to that presented herein for stainless steel was conducted for structural carbon steel. The full details of this investigation are available elsewhere [9] and a brief summary is included hereafter, to facilitate a comparison of the key findings. This study included 718 individual post-fire tensile tests, of which 187 experiments were on low alloy steel with a yield strength of up to $420 \mathrm{~N} / \mathrm{mm}^{2}$; these are the most relevant for comparison with the stainless steels studied in this paper. Figure 15 presents a comparison of the proposed retention factors $\left(\mathrm{R}_{\theta}\right)$ for carbon steel (CS) and stainless steel (SS) for (a) yield strength, (b) ultimate strength, (c) ultimate strain and (d) Young's modulus. Figure 15 shows the behaviour of carbon steels (CS) as a grey dashed line, stainless steels without the ferritic grades as a black solid line (SS $\backslash F)$ and then including the ferritic grades as a grey dotted line (SS). The main observations are summarised hereafter:

- Yield strength: For stainless steel, a full retention of the yield strength is obtained until an exposure temperature of $750^{\circ} \mathrm{C}$. For carbon steel, the full recovery is however limited to a temperature of $600^{\circ} \mathrm{C}$.

- Ultimate strength: As shown in Figure 15(b), there are no significant differences between the observed behaviours of stainless and carbon steels, post-fire.

- Ultimate strain: With reference to Figure $15(\mathrm{c})$, between $200^{\circ} \mathrm{C}$ and $800^{\circ} \mathrm{C}$, structural carbon steels exhibits slightly lower retention compared with stainless steels. However, following exposure to $800^{\circ} \mathrm{C}$ and above, stainless steel recovers less of its initial ultimate strain compared with carbon steel. It is noteworthy that this is mainly owing to the behaviour of ferritic stainless steel. If these grades are removed from the stainless steel analysis, the austenitic and duplex grades perform significantly greater than carbon steel and recover most of their ductility after the fire.

- Young's modulus: The retention factor for Young's modulus for both carbon and stainless steels is very good and is marginally better overall for carbon steel. Nevertheless, the loss in stiffness is limited to $10 \%$ of the original values over the full temperature range examined herein for both materials. 


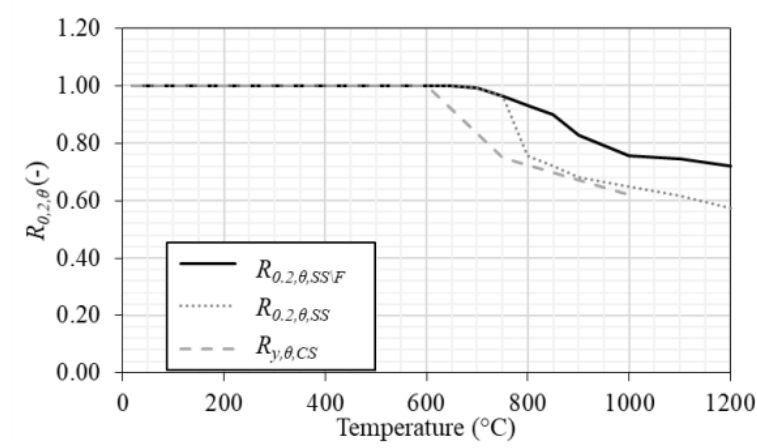

a)

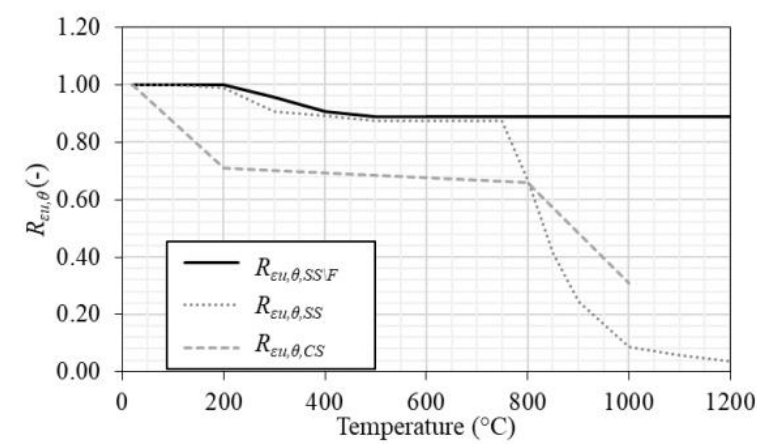

c)

Figure 15 Comparison of the post-fire retention factors for carbon steel and stainless steel for a) yield strength, b) tensile strength, c) ultimate strain and d) Young's modulus.

\section{Uncertainty aspects}

In light of the above discussion, and the relationship between reliability, uncertainly, and partial factors as employed in design, in the current section, determination of the fractile factors $k_{n}$ is considered, in accordance with the codes. In the case that the standard deviation of the mechanical properties' distribution function increases following exposure to fire and subsequent cooling, compared with the original ambient values, it is necessary to re-consider the safety factors used in design. The current work is focussed mainly on existing structures for which the remaining lifetime might be reduced and therefore adjustments to the reliability level are also required. An optimized target reliability considering economic and social aspects for existing structures can compensate for the adverse impact of the increasing uncertainties, as is discussed herein.

\subsection{Safety factors}

In Eurocode 0, the design value of a resistance variable is divided by its characteristic value to determine an appropriate material partial factor (or factor of safety, $\gamma_{M 0, \theta}$ ) as presented in Eq. 2 [23]: 


$$
\gamma_{M 0, \theta}=\frac{X_{k, \theta}}{X_{d, \theta}}=\frac{\exp \left(-1.645 \sqrt{\ln \left(V_{\text {test } \left., \theta^{2}+1\right)}\right)}\right.}{\exp \left(-\alpha \beta \sqrt{\ln \left(V_{\text {test } \left., \theta^{2}+1\right)}\right)}\right.}
$$

In this expression, $X_{k, \theta}$ and $X_{d, \theta}$ are the characteristic and design values of the considered property, respectively, and $V_{\text {test }, \theta}$ is the coefficient of variation from a particular post-fire test where the elevated temperature reached is $\theta$. The base material property is characterized by a certain coefficient of variation at each temperature $\theta$. The sensitivity factor $\alpha_{R}$ for resistance effects has a value of 0.8 in accordance with Eurocode 0 [23] and the reliability factor $\beta$ for new structures in Consequence Class 2 (CC2) is equal to 3.8 [23]. The $\mathrm{CC} 2$ class refers to a medium consequence for loss of human life, while economic, social or environmental consequences are rated as being considerable. Examples of CC2 structures include residential and office buildings, as well as public buildings with a medium consequence of failure.

In the current analysis, the coefficient of variation from a test $V_{\text {test }}$ (or $\left.V_{\text {test }, \theta}\right)$ is the ratio of the corresponding coefficient of variation of the virgin material $\left(V_{a m b}\right)$ and the coefficient of variation of the post-fire material $\left(V_{p o s t}\right)$, and is dependent on the level of temperature exposure. It is expressed in Eq. 3, where $V_{a m b}$ is given in Table 3:

$$
V_{\text {test }}^{2}=V_{a m b}^{2}+V_{\text {post }}^{2}
$$

The characteristic value of a particular mechanical property is determined in accordance with Eq. 4:

$$
X_{k}=\exp \left(\mu_{y} \pm k_{n} \sqrt{\left(V_{\text {test }}^{2}-V_{a m b}^{2}\right)}\right)
$$

As previously mentioned, the current work builds on another similar study that focussed on the postfire behaviour of carbon steel [9] in which a simplified method to obtain the relevant partial factor is described. In this, it was described that for low alloy structural carbon steels, the JCSS Code of Practice [24] proposes a series of coefficients of variation based on tests executed under ambient conditions $\left(V_{a m b}\right)$. For stainless steel however, these do not apply. It is noteworthy that for stainless steel, the material safety factor $\gamma_{M 0}$ in Eurocode 3 Part 1-4 is given as 1.10, which corresponds to a coefficient of 
variation $V_{a m b}$ of 0.07 . Therefore, using a similar approach to that which was described in the study into post-fire behaviour and reliability of carbon steels [9], the fractile factor $k_{n}$ and safety factor $\gamma_{M 0, \text { post }}$ can be determined herein based on the data available.

The safety factor in the post-fire condition $\left(\gamma_{M 0, \text { test }}\right)$ is determined as the product of the safety factors for the material properties in ambient conditions (i.e. $\gamma_{M 0, a m b}=1.10$ ) and a second safety factor specifically for the post-fire circumstances (i.e. $\gamma_{M 0, p o s t}$ ), as given in Eq. 5 .

$$
\gamma_{M 0, t e s t}=\gamma_{M 0, a m b} \times \gamma_{M 0, p o s t}
$$

In the ideal case, the product of both safety factors $\left(\gamma_{M 0, a m b}\right.$ and $\left.\gamma_{M 0, p o s t}\right)$ should equal the value directly resulting from the previously mentioned coefficient of variation $\left(\gamma_{\mathrm{M} 0 \text {,test }}\right)$ which however is not always the case. It has been shown by other researchers (König \& Hosser, 1982) that, for the non-dominant variable, the sensitivity factor $\alpha_{R}$ should be taken as the product of 0.4 and 0.8 i.e. 0.32 . Since $V_{\text {post }}$ depends on temperature, it is non-dominant in the lower temperature regions and becomes more dominant when the material is exposed to higher temperatures. The resulting safety factors $\left(\gamma_{M 0}\right)$ for the data considered in the current study, accounting for this, are depicted in Figure 16 for (a) all grades of stainless steel, (b) austenitic stainless steels, (c) duplex grades and (d) ferritic stainless steels.

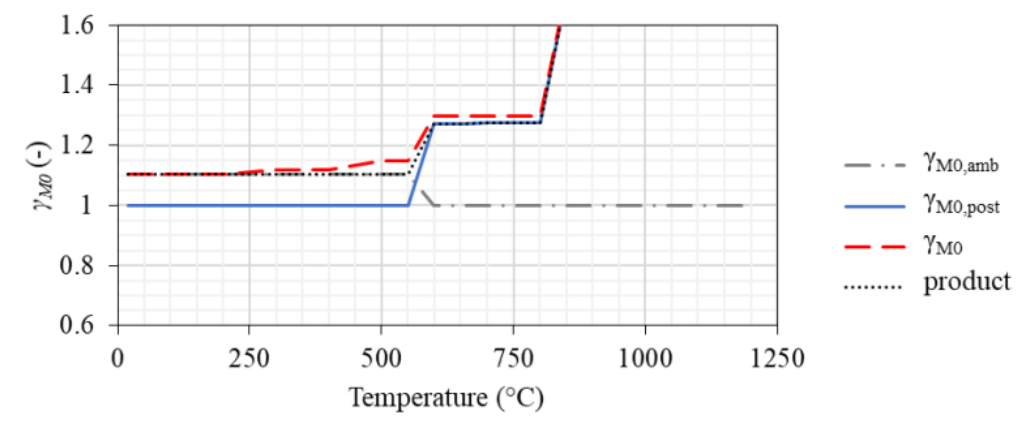

a)

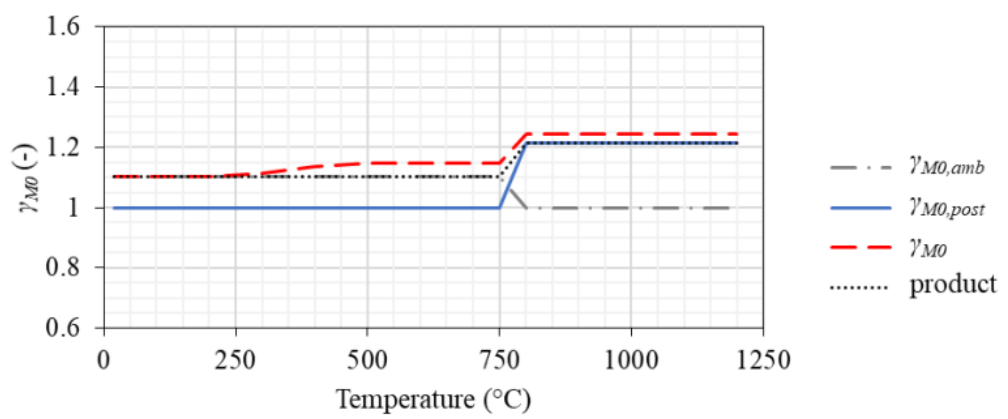


b)

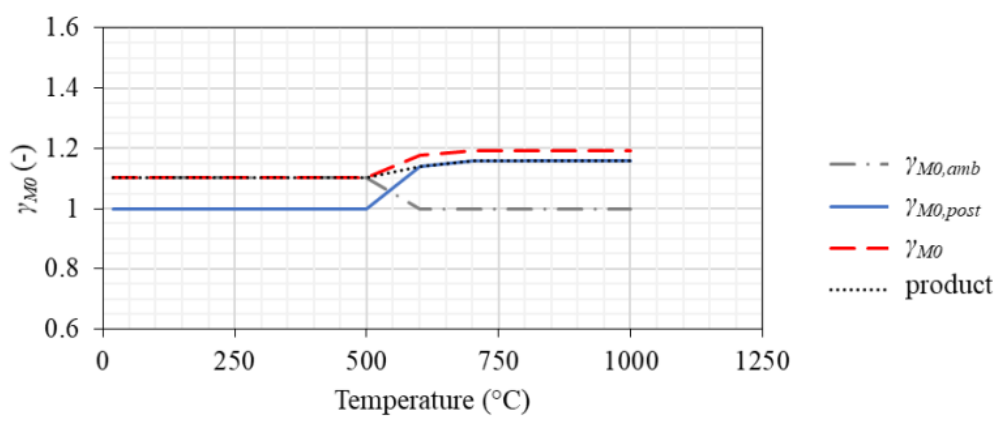

c)

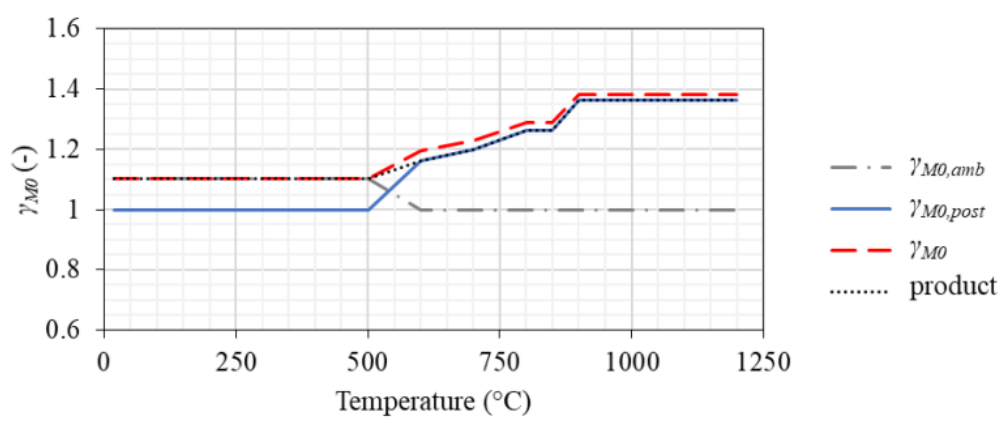

d)

Figure 16 Summary of the determined safety factors with a reliability index $\beta=3.8$ for a) all grades, b) austenitic, c) duplex and d) ferritic stainless steels.

The proposed safety factors $\left(\gamma_{M 0, p o s t}\right)$ for the different grades of stainless steel considered in this study are given in Table 6. With reference to these values and the data presented in Figure 16, the following observations are noteworthy:

- $\quad$ From Figure 16(a), for all grades it is clear that for samples that are exposed to temperatures of at least $550^{\circ} \mathrm{C}$, the ambient safety factor of 1.10 should be replaced by a more appropriate value of 1.3 . Above $800^{\circ} \mathrm{C}$, this safety factor increases to 1.60 , which corresponds to a coefficient of variation of 0.34. This results in a structure with a design load of $62.5 \%$ of its original, pre-fire, value which may render its reinstatement as uneconomical.

- $\quad$ For the austenitic grades (Figure 16(b)), for the post-fire behaviour of materials subjected to $500^{\circ} \mathrm{C}$ and above, there is a slight influence from the fire on the mechanical properties and an 
appropriate value for $\gamma_{M 0, p o s t}$ is 1.15 . After exposure to higher temperatures, $750^{\circ} \mathrm{C}$ and above, the propsed safety factors is 1.25 .

- For the duplex grades, it is recommended that the safety factor is revised to 1.20 for material that is exposed to temperatures between $500^{\circ} \mathrm{C}$ and $1000^{\circ} \mathrm{C}$. For higher temperatures, these is insufficient data to propose a recommended value.

- In Figure 16(d), it is shown that for the ferritic grades, a two-step approach is appropriate, with a safety factor of 1.25 adopted for exposure temperatures between $500^{\circ} \mathrm{C}$ and $850^{\circ} \mathrm{C}$ and then a value of 1.40 for higher fire temperatures.

Table 6 Critical temperatures and proposed safety factors for stainless steel with $\beta=3.8$.

\begin{tabular}{lll}
\hline Material & $\theta\left({ }^{\circ} \mathrm{C}\right)$ & Safety factor $\gamma_{M 0, \text { post }}$ \\
\hline All grades stainless steel & $>550$ & 1.30 \\
\hline & $\theta_{\lim }>850$ & $>1.60$ \\
\cline { 2 - 3 } Austenitic stainless steel & $>500$ & 1.15 \\
\hline & $>750$ & 1.25 \\
\hline Duplex stainless steel & $>500$ & 1.20 \\
\hline Ferritic stainless steel & $>500$ & 1.25 \\
& $>850$ & 1.40 \\
\hline
\end{tabular}

\subsection{Influence of the reliability index on safety factors}

For buildings categorized in normal consequence class 2 [23], the reliability index $\beta$ of 3.8 as considered earlier in this paper, corresponds to a probability of failure of $7.23 \times 10^{-5}$. It has previously been shown by a number of researchers [25], [26] that a distinction should be made between new, existing and temporary structures in terms of their reliability indexes, and a lower value may be appropriate in some circumstances. In accordance with ISO 2394 [27], for an existing building in the post-fire condition a lower limit $\beta$ value of 3.3 may be appropriate, for which societal and human risks are considered to be satisfactory [25]. This has a direct influence on the safety factor $\gamma_{M 0, p o s t}$, resulting in lower values than those determined using $\beta=3.8$, as shown in Figure 17 and the values given in Table 7 . With reference to the values in Table 7 (determined with $\beta=3.3$ ), compared with those in Table 6 for $\beta=3.8$, the influence of using a lower reliability index on the safety factor is rather limited. 


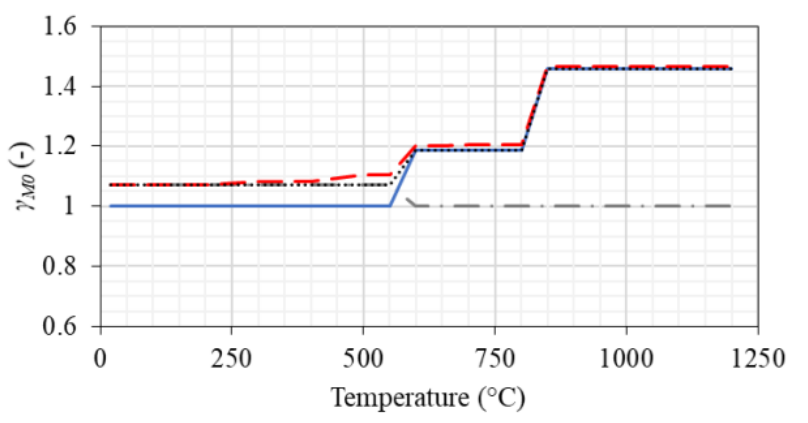

$$
\begin{aligned}
& -\cdot-\gamma \mathrm{M} 0, \mathrm{amb} \\
& -\gamma \mathrm{M} 0, \mathrm{post} \\
& --\gamma \mathrm{M} 0 \\
& \cdots \cdots \cdots \cdot \text { product }
\end{aligned}
$$

a)

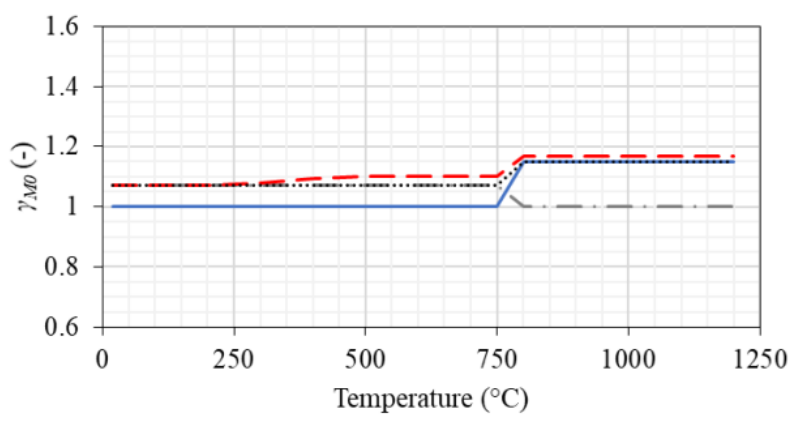

$$
\begin{aligned}
& -\cdot-\gamma \mathrm{M} 0, \mathrm{amb} \\
& -\gamma \mathrm{M} 0, \mathrm{post} \\
& --\gamma \mathrm{M} 0 \\
& \cdots \cdots \cdot \cdots \text { product }
\end{aligned}
$$

b)

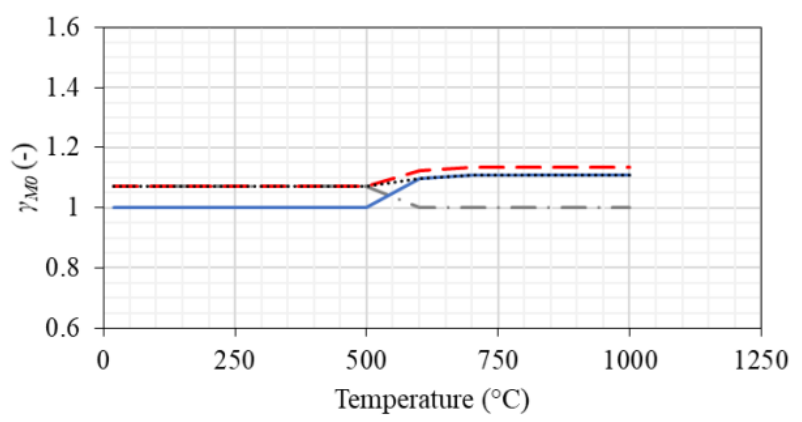

$$
\begin{aligned}
& -\cdot-\gamma \mathrm{M} 0, \mathrm{amb} \\
& -\gamma \mathrm{M} 0, \mathrm{post} \\
& --\gamma \mathrm{M} 0 \\
& \cdots \cdots . . . \text { product }
\end{aligned}
$$

c)

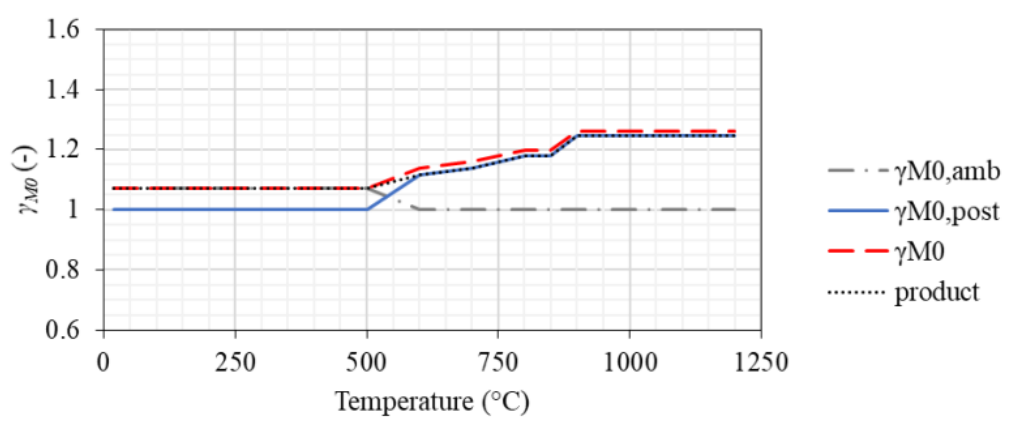

d)

Figure 17 Summary of the determined safety factors with a reliability index $\beta=3.3$ for a) all grades, b) austenitic, c) duplex and d) ferritic stainless steels. 
Table 7. Critical temperatures and proposed safety factors for stainless steel with $\beta=3.3$.

\begin{tabular}{lll}
\hline Material & $\theta\left({ }^{\circ} \mathrm{C}\right)$ & Safety factor $\gamma_{M 0, p o s t}$ \\
\hline All grades of stainless steel & $>600$ & 1.20 \\
\hline & $>800$ & 1.45 \\
\hline Austenitic stainless steel & $>750$ & 1.15 \\
\hline Duplex stainless steel & $>500$ & 1.15 \\
\hline Ferritic stainless steel & $>500$ & 1.20 \\
& $>850$ & 1.25 \\
\hline
\end{tabular}

\section{Conclusions}

At the current time in which sustainability and environmental challenges are so important globally, the ability to re-use and rehabilitate structures following an extreme event, reducing the need for new materials and demolition, is significant. In this context, this paper studies the post-fire behaviour of structural stainless steels. In the first instance, an experimental study into both loaded and unloaded virgin austenitic stainless steel coupons is presented and analysed. The influence of cooling method is also studied. It is shown that loading has very little effect on mechanical response to heating and subsequent cooling, although a strain hardening effect is seen in the high shear regions. Moreover, for the range of coupons examined herein, the influence of cooling the specimens quickly in water, or allowing them to cool naturally in the furnace, is minimal.

Secondly, an extensive literature review is conducted on different grades of stainless steel test coupons subjected to high temperature and then cooled in a controlled environment. The material characteristics such as proof strength, ultimate strength, ultimate strain and Young's modulus are summarised and analysed. It is demonstrated that the most commonly used grades of stainless steel retain most of their strength and stiffness after exposure to very high temperatures. The results also show that the heating level, cooling method and sample thickness are all influential to the retention of strength and stiffness after fire.

In the final part of the paper, the coefficient of variation on the post-fire material properties $\mathrm{V}_{\text {post }}$ is evaluated for a range of temperatures, based on the collated experimental data. The influence of reliability index $\beta$ is examined, particularly in terms of the coefficient of variation from the tests $\mathrm{V}_{\text {test }}$ and the post-fire safety factor $\gamma_{M 0, p o s t}$. This is very important and relevant for the reinstatement of 
stainless steel structures following exposure to fire and subsequent cooling, and it is shown that the partial factor varies depending on the maximum exposure temperature. For the austenitic or duplex stainless steel grades, if the stainless steel is exposed to a temperature of $750^{\circ} \mathrm{C}$ or $500^{\circ} \mathrm{C}$, respectively, the safety factor $\gamma_{M 0, p o s t}$ should be increased to 1.15 . For the ferritic grades, however, above $500^{\circ} \mathrm{C}$, $\gamma_{M 0, p o s t}$ should be 1.20 .

In conclusion, the following procedure is recommended in the post-fire assessment of stainless steel structures: depending on the maximum temperature reached during the fire, select the retention factor from Table 5 to reflect the changes in the material properties and the additional safety factor from Table 7 to cover the increased variability in the results.

\section{References}

[1] B. Karabulut, G. Lombaert, D. Debruyne and B. Rossi, "Optimized design and life cycle cost analysis of a duplex welded girder bridge," Ghent, 2018.

[2] B. Rossi, "Discussion on the us of stainless steel in constructions in view of sustainability," ThinWalled Structures, no. 83, pp. 182-189, 2014.

[3] EN 1993-1-4, Design of steel structures - Part 1-4: General Rules - Supplementary Rules for Stainless Steels, Including Amendement A1, Brussels, Belgium: CEN, $2006+$ A1:2015.

[4] SCI, Design Manual for Structural Stainless Steel, 4th edition, Berkshire, UK: SCI, 2017.

[5] EN 10088-2, Stainless steels - Part 2: Technical delivery conditions for sheet/plate and strip of corrosion resisting steels for general purposes, Brussels: CEN, 2005.

[6] M. Holicky and J.-B. Schleich, "Chapter IV - Life Safety Considerations," in Handbook 5 Design of buildings for the fire situation, Luxemburg, GDL, Leonardo Da Vinci Pilot Project CZ/02/B/F/PP-134007, 2005, pp. IV-1-9.

[7] M. Malaska, K. A. Cashell, M. Alanen, K. Mela and S. Afshan, "Experimental behaviour of stainless steel cellular beam in fire," in Nordic Steel Construction Conference, Copenhagen, Denmark, 2019.

[8] M. H. Faber, Risk Assessment in Engineering - Principles, System Representation \& Risk Criteria, Copenhagen, Denmark: JCSS, 2008.

[9] T. Molkens, K. A. Cashell and B. Rossi, "Post-fire mechanical properties of carbon steel and safety factors for the reinstatement of steel structures," Submitted, 2020. 
[10] K. A. Cashell, M. Malaska, M. Khan, M. Alanen and K. Mela, "Numerical analysis of the behaviour of stainless steel cellular beam in fire," in Nordic Steel Conference, Copenhagen, Denmark, 2019.

[11] EN 1993-1-2, Design of steel structures - Part 1-2: General rules - Structural fire design, Brussels: CEN, 2004.

[12] EN 10002-1, Metallic materials - Tensile testing - Part 1: Method of test at ambient temperature, Brussels: CEN, 1990.

[13] Y. Huang and B. Young, "The art of coupon tests," Journal of Constructional Steel Research, no. 96, pp. 159-175, 2014.

[14] EN 6892-1, Metallic materials - Tensile testing - Part 1: Method of test at room temperature (ISO 6892-1: 2019), Brussels: CEN, 2020.

[15] X. Wang, Z. Tao, T. Song and L. Lan, "Stress-strain model of austenitic stainless steel after exposure to elevated temperatures," Journal of Constructional Steel Research, no. 99, pp. 129$139,2014$.

[16] R. Felicetti, P. G. Gambarova and A. Meda, "Residual behaviour of steel rebars and R/C sections after fire," Construction and Building Materials, no. 23, pp. 3546-3555, 2009.

[17] Y. Huang and B. Young, "Post-fire behaviour of ferritic stainless steel materials," Construction and Building Materials, no. 157, pp. 654-667, 2017.

[18] X. Gao, X. Zhang, H. Liu, Z. Chen and H. Li, "Residual mechanical properties of stainless steels S30408 and S31608 after fire exposure," Construction and Building Materials, no. 157, pp. 654$667,2017$.

[19] Z. Tao, X.-Q. Wang, M. K. Hassan, T.-Y. Song and L.-A. Xie, "Behaviour of three types of stainless steel after exposure to elevated temperatures," Journal of constructional steel research, no. 152 , pp. 296-311, 2018.

[20] Y. Huang and B. Young, "Mechanical properties of lean duplex stainless steel at post-fire condition,” Thin-Walled Structures, no. 130, pp. 564-576, 2018.

[21] Y. Hu, S.-L. Tang, A. George, Z. Tao, X.-Q. Wang and H.-T. Thai, "Behaviour of stainless steel bolts after exposure to elevated temperatures," Journal of Constructional Steel Research, no. 157, pp. 371-385, 2019.

[22] EN 1363-1, Fire resistance tests - Part 1: General requirements, Brussels: CEN, 2012.

[23] EN 1990, Eurocode 0 Basis of structural design (consolidated version including A1:2005 and AC:2010), Brussels, Belgium: CEN, 2015.

[24] JCSS, Probabilistic model code: Part 3 - Resistance models, Copenhagen, Denmark: DTU, 2000.

[25] M. Sykora, D. Diamantidis, M. Holicky and K. Jung, "Target reliability levels for existing structures considering economic and societal aspects," Structure and Infrastructure Engineering, no. 13, pp. 181-194, 2017. 
[26] R. Caspeele, M. Sykora, D. L. Allaix and R. Steenbergen, "The design value method and adjusted partial factor approach for existing structures," Structural Engineering International, vol. 23, no. (4), pp. 386-393, 2013.

[27] ISO 2394, General principles on reliability of structures (4th ed.), Geneve: ISO/TC98, 2015. 